\title{
FAIR TRADE - IS IT REALLY FAIR?
}

\section{Tomáš Konečný Jan Mysliveček}
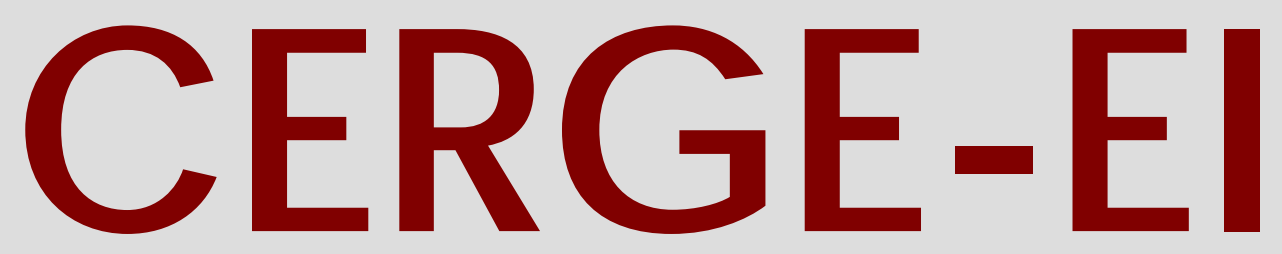

Charles University Centerfor Economic Research and Graduate Education Academy of Sciences of the Czech Republic Ec onomic s Institute 


\title{
Working Paper Series 367 (ISSN 1211-3298)
}

\section{Fair Trade - Is It Really Fair?}

\author{
Tomáš Konečný \\ Jan Mysliveček
}

CERGE-EI

Prague, September 2008 
ISBN 978-80-7343-167-9 (Univerzita Karlova. Centrum pro ekonomický výzkum a doktorské studium)

ISBN 978-80-7344-156-2 (Národohospodářský ústav AV ČR, v.v.i.) 


\title{
Fair Trade-Is It Really Fair? Tomáš Konečný, Jan Mysliveček* CERGE-EI ${ }^{\dagger}$
}

\begin{abstract}
:
One of the arguments against the Fair Trade scheme is that the guaranteed minimum price tends to depress world prices and thus the incomes of non-participating farmers (e.g. The Economist, 2006). We develop a model that distinguishes between the impact of the introduction of a Fair Trade market per se and the effect of minimum price policies given that a Fair Trade market actually exists. The model suggests that the claims against Fair Trade might not be correct. The introduction of a Fair Trade market may increase the incomes of both participating and non-participating farmers. The minimum contracting price as part of Fair Trade standards, however, precludes the full realization of the program's potential benefits. The minimum price also paradoxically increases the profits of the middlemen whose local monopsony power the Fair Trade scheme originally aimed to retrench. Furthermore, the total surplus generated by Fair Trade cooperatives declines as the guaranteed price increases.
\end{abstract}

\begin{abstract}
Abstrakt:
Jedním z argumentů proti Fair Trade obchodu je, že minimální garantovaná cena snižuje světové ceny komodit a tedy i př́ijmy farmářů, kteří se Fair Trade neúčastní (např. The Economist, 2006). My sestavujeme model, který umožňuje rozlišit mezi dopady způsobené vytvořením Fair Trade trhu a efektem způsobeným minimální cenou na existujícím trhu. Výsledky ukazují, že argumenty proti Fair Trade nemusejí být pravdivé. Zavedení Fair Trade může zvýšit př́jmy všech výrobců. Minimální garantovaná cena ale omezuje plné čerpání všech výhod Fair Trade programu. Paradoxně totiž zvyšuje zisky prostředníki̊, přičemž jejich monopsoní pozice byla důvodem vznikem Fair Trade. Zvyšovaní minimální garantované ceny snižuje celkový přínos pro Fair Trade družstva.
\end{abstract}

Keywords: Certification, regulation, price setting, coffee, Fair Trade, monopsony JEL classification: D18, D21, D43, D45, D71, J51, Q17, Q56

\footnotetext{
*We would like to thank Levent Çelik, Libor Dušek, Peter Katuščák, Dilip Mookherjee, Andreas Ortmann, Avner Shaked, Eric Verhoogen and Krešimir Žigič for their comments. Jan Mysliveček thanks the University of California, San Diego for its hospitality and the Fulbright Commission for its support. All remaining errors are ours.

${ }^{\dagger}$ CERGE-EI is a joint workplace of the Center for Economic Research and Graduate Education, Charles University, and the Economics Institute of Academy of Sciences of the Czech Republic.

Address: CERGE-EI, PO Box 882, Politických vězňů 7, 11121 Prague, Czech Republic. E-mail: tomas.konecny@cerge-ei.cz, jan.myslivecek@cerge-ei.cz.
} 


\section{Introduction}

As Fair Trade-certified products gradually move from specialized shops to supermarket shelves, the actual impact and potential of Fair Trade has become an increasingly discussed topic. Academics, journalists and policymakers as well as NGOs and other stakeholders involved in the Fair Trade scheme present their worries and expectations regarding the movement's actual capacity to improve the livelihoods of poor people. Besides the common assertion that Fair Trade certification helps marginalized producers through guaranteed minimum prices and other provisions like access to pre-finance or market information (FLO, 2007), the most vocal concerns of Fair Trade opponents relate to the excess Fair Trade supply, the impact on non-participating producers, and the uncertain nature of Fair Trade demand (The Economist (2006), Washington Post (2005), Weber (2007), etc.). ${ }^{1}$ These opinions certainly deserve a more detailed analysis as the potential reach of Fair Trade extends to millions of households living in poverty.

This paper aims to address some of the most frequently expressed concerns relating to the Fair Trade certification scheme, namely the excess of Fair Trade supply due to the guaranteed minimum price, the impact on non-participating producers, and the limited scope of Fair Trade demand. In particular, it aims to answer the following questions: What is the impact of the introduction of Fair Trade markets on farmers' incomes? Does the guaranteed Fair Trade price disadvantage those producers who do not engage in Fair Trade compared with those who do? How do the costs and benefits of the scheme depend on the structure of global markets?

We develop a simple framework incorporating the empirical regularities of the largest and most successful Fair Trade market - coffee. Within this framework we distinguish between the impact of the introduction of a market with Fair Trade-certified products ${ }^{2}$ and the effect of minimum price policies given that a Fair Trade market actually exists. Furthermore, we study the link between the two abovementioned measures and the behavior of monopsonistic middlemen operating in regional coffee markets.

The following section provides a brief expose of the structural changes on the global coffee market in the 90s and the success of Fair Trade-labelled coffee. Section 3 reviews the organization of the Fair Trade labelling scheme and the major arguments favoring

\footnotetext{
${ }^{1}$ There are, of course, additional arguments against Fair Trade such as the inefficiencies in processing and distribution due to Fair Trade's bypassing of specialized intermediaries exploiting economies of scale. Fair Trade has also been criticised as yet another instrument for price discrimination across customers. For the sake of clarity, our paper does not address these issues and instead focuses exclusively on the excess supply argument and the corresponding impact on farmers.

${ }^{2}$ The assumption that there indeed exists a demand for such products can be justified by Andreoni (1990)'s "warm glow" effect. In the present context, the "warm glow" effect reflects the additional utility due to the consumption of coffee grown under "fair" standards.
} 
the Fair Trade idea. Section 4 develops a model that addresses some of the benefits and concerns relating to Fair Trade in a simple framework first without monopsonistic middlemen and then with the middlemen that control access to world markets. For ease of exposition, Section 4 also contains the numerical results obtained from explicit supply and demand structures. The final section concludes.

\section{Fair Trade and the global coffee market}

The Fair Trade idea is usually associated with coffee, the most successful Fair Trade commodity with the largest share in total sales and the longest history among traded Fair Trade commodities. ${ }^{3}$ The growth of Fair Trade can be neatly illustrated by the story of this commodity. The yearly average increase in total sales volume of Fair Trade coffee over the period 2001-2006 amounted to 27\%, with growth rates increasing on a yearly basis and reaching as much as 53\% in 2006 (FLO, 2007). The extraordinary growth can be attributed mostly to the expanding markets in the United States, where only in 2006 the sales volumes more than doubled. Nonetheless, in Europe with its 79,000 salespoints, the market shares of Fair Trade coffee have been likewise increasing substantially. In the United Kingdom, the market share of ground Fair Trade coffee increased from 1.5\% in 1999 to $20 \%$ in 2004 (FINE, 2005). ${ }^{4}$ While in other European countries the growth rates and market shares have been more modest, they still exceed the annual growth of world coffee demand $(0.4 \%)$ by an order of magnitude. Hence, despite a still negligible share in the overall world coffee consumption $(0.8 \%$ out of a total 6.7 million tons in 2006, FLO (2007) and ICO (2007)), ${ }^{5}$ the continuing expansion of specialty markets and rising consumer awareness of the Fair Trade concept ${ }^{6}$ call for a closer evaluation of the respective pros and cons. We begin with developments on the world coffee markets over the last few decades.

\footnotetext{
${ }^{3}$ In North America, coffee accounted for 34\% of all Fair Trade sales in 2003 EFTA (1998). According to the European Commission (1999), the estimated share of Fair Trade food products totaled $60 \%$ of the overall Fair Trade retail turnover within the EU. Coffee made up approximately $50 \%$ of the abovementioned share.

${ }^{4}$ Note that the figures refer to ground coffee, for instant coffee the shares are much lower (FLO, 2007).

${ }^{5}$ According to the FLO (2007), the worldwide certified sales of all Fair Trade products amounted to roughly $2.3 \mathrm{bln}$ USD. The overall sum will be slightly higher given that the figure does not include non-certified Fair Trade articles. Given this minor share, one could argue that the cross-price effects impacting the non-participating farmers are likely to be rather tame, if any. In Section 4 we argue that this might not be the case.

${ }^{6}$ Moore (2004) cites survey evidence on expanding shares of consumers describing themselves as "ethical", or "strongly ethical".
} 


\subsection{Coffee crisis in the $90 \mathrm{~s}$}

Until 1989, the global coffee market was regulated through the International Coffee Agreement (ICA), a set of agreements which stipulated production quotas and governed quality standards for the majority of produced coffee. The disintegration of the ICA and the following sharp rise in coffee supply coincided with stagnating demand and market concentration of major roasting and trading companies. On the supply side, the quota abolition led to the output expansion of existing producers (e.g., Brazil), as well as the entry of new significant players (Vietnam) specializing in the production of lower quality Robusta coffee. The demand side, on the other hand, witnessed improved processing technologies that removed the bitter taste of cheaper coffee beans such as Robusta and "natural" Arabica. These advances shifted roasters' demand away from traditional coffee exporters from Central America specializing in a more expensive mild Arabica (Lindsey, 2003). ${ }^{7}$ The coffee glut has been further exacerbated by the long adjustment lags typical for coffee production. ${ }^{8}$

Except for short periods of recovery in the mid-90s, coffee prices reached historical lows and led to substantial hardship in the affected rural economies. ${ }^{9}$ In October 2001, the price of higher quality Arabica coffee ${ }^{10}$ quoted at the New York Board of Trade reached its lowest level in 30 years at 45 cents/lb. For the sake of comparison, Bacon (2005) puts the estimated average monetary production costs of small farm producers to vary between 49 and 79 cents/lb. Nonetheless, since 2001 the price of Arabica coffee has gradually risen so that in October 2007 it has surpassed the Fair Trade minimum price 121 cents/lb.

\subsection{Shifts in market power}

In general, coffee beans leaving a farm have to pass several intermediate stages before they reach the final consumer. Harvested beans are usually purchased by a private intermediary. They are further processed and distributed by a processing plant, local exporters and/or international traders, and retailers. The coffee crisis in the 90s coincided with the extended upstream integration of the commodity chain. While sluggish

\footnotetext{
${ }^{7}$ According to Wasserman (2002), cited in Lindsey (2003), the estimated percentage of mild Arabica in the roasters' leading coffee blends dropped from 50\% in 1989 to $35 \%$ in 2001.

${ }^{8}$ It takes several years before beans can be first harvested.

${ }^{9}$ Bacon (2005) mentions substantial rural-urban migration in Matagalpa, Nicaragua and eroded farmlands following the substitution from coffee to cattle pasture in Coto Brus, Costa Rica. Similar observations from other regions can be found in e.g. Raynolds (2002) or Ronchi (2002).

${ }^{10}$ Arabica and Robusta are the two main coffee species produced. While Arabica is grown mostly in Latin America and Eastern Africa, major producers of Robusta coffee are located in Brazil, Uganda, India and South-East Asian countries (ICO, 2007).
} 
coffee demand and general market liberalization facilitated corporate consolidation in the lower parts of the commodity chain, the empty space left by the retreating government involvement after the disintegration of the ICA has been swiftly resumed by the roasters and trading companies (Ponte (2002) cited in Bacon (2005)). In fact, the coffee roasting market happens to be the most heavily concentrated part of the commodity chain. The two largest groups, Nestlé and Philip Morris, control $49 \%$ of the world market for roasted and instant coffees. The following roasters-Sara Lee, Procter and Gamble and Tchibo - make up an additional 20\%. Less but still highly concentrated are international traders. The two largest international coffee traders as of 1998, Neusmann and Volcafé, controlled 29\% of the market, and the top six companies $50 \%$ (Milford, 2004).

An increase in the concentration of the intermediate and downstream parts of the value chain also led to a decrease in the revenue share for producing countries. Talbot (1997) cited in Bacon (2005) reports producer countries' share of the final retail price decreased from close to $55 \%$ in the past to about $22 \%$. More recent estimates suggest that farmers get about $6 \%$ of the value of the price of coffee in the store (Milford, 2004). ${ }^{11}$

\subsection{Growth of specialty markets}

While demand for normal "bulk" coffee has been stagnating and its prices have been falling, the specialty coffee sector has been growing fast. For example, the U.S. gourmet coffee market in 2001 represented $40 \%$ of the total market value and $17 \%$ by volume with annual growth rates well above $5 \%$ (Giovanucci, 2001). The continuing success of specialty brands has reflected increasing consumer demand for high quality, taste and an attractive "story" behind each cup of coffee. The Fair Trade and organic labels were able to keep up with these market differentiation trends and although they represent still a relatively minor share in the specialty coffee sector $(3-5 \%$ in the U.S. specialty coffee retail market (Giovanucci, 2001)), their position becomes stronger year-by-year. Apart from increasing market shares in the gourmet sector, the growing importance of Fair Trade in the coffee market becomes apparent from both its increasing recognition by customers and widening presence in common distribution channels. The former can be illustrated by survey evidence according to which $74 \%$ of the French population understood the notion of Fair Trade and $50 \%$ of the adult population in the UK recognized the Fair Trade label (FINE, 2005). Fair Trade products have also become increasingly available in "mainstream" retail outlets. In Europe only, the number of supermarkets

\footnotetext{
${ }^{11}$ An illuminating contribution on primary producer shares in the context of markets for cocain and heroin is Miron (2003).
} 
with a Fair Trade selection increased from 43,100 in 1999 to 56,700 in 2004 (FINE, 2005), i.e., by $32 \%$. The origins, organization and working of Fair Trade networks facilitating the above-mentioned market progress is described in more detail in the following section.

\section{The origins, organization and benefits of Fair Trade}

The origins of the Fair Trade movement can be traced back more than 40 years when Alternative Trade Organizations (ATO) established trade networks connecting marginalized producers in developing countries with socially aware customers in developed markets. These entities were run mostly by religious organizations and various solidarity groups with the aim to provide a viable alternative to what they perceived as inequitable world market relations. ATO's initial efforts, however, did not succeed in transforming the Fair Trade idea into a major alternative to the existing system. In order to gain a new impetus, the ATO's initial focus on handicrafts gradually shifted towards agricultural commodities and in 1988, the first certification scheme introduced by a Dutch ATO, Solidaridad, started a qualitatively new era of Fair Trading. Through the guarantee that labelled products meet basic environmental and labor standards, the Solidaridad's novel label Max Havelaar simplified the interface between participating producers and customers in developed markets and by so doing set the basis for the future successful entry of Fair Trade into mainstream distribution channels. Max Havelaar's success has been followed by similar projects. In 1997 several independent labelling initiatives formed Fairtrade Labelling Organization International (FLO). ${ }^{12} \mathrm{Fi}$ nally, in 2002 the FLO launched the FairTrade label in order to harmonize different labels used at the time. While some of the initiatives decided to stick to their current labels, they nonetheless adhere to the standards set by the FLO.

The FLO is itself an umbrella organization of 20 labelling initiatives in 21 countries and 3 producer networks. The organization currently works with 569 Fair Trade-certified producer organisations representing over 1.4 million farmers and workers in 57 countries in Africa, Asia and Latin America (FLO, 2007). Similar to other Fair Trade initiatives,

\footnotetext{
${ }^{12} \mathrm{FLO}$ is one of four members of the umbrella organization FINE, which also includes the International Fair Trade Association, the Network of European Worldshops and the European Fair Trade Association. The ultimate goal of each participating organization is to facilitate Fair Trade, yet only FLO serves as a certification and standard-setting body. In North America, the most important organization is the Fair Trade Federation (FTA). FTA is an association of Canadian and American fair trade wholesalers, importers and retailers providing matching services and diffusing information about Fair Trade.
} 
the FLO supports Fair Trade through the linking of producers with traders in order to match supply and demand, liaison with producer organizations to strengthen their production and export capacities, and lobbying at international forums on trade and development. Nonetheless, the main task of the FLO is the standard setting, certification and monitoring of the Fair Trade Certification Trademark recipients.

\subsection{Fair Trade and labelling}

Of course, coffee is not the only Fair Trade article and not all Fair Trade products are certified. According to FLO data, the retail value of all Fair Trade products sold in 14 European countries in 2005 totaled $€ 657 \mathrm{~m}$ at minimum, out of which $€ 597 \mathrm{~m}$ (i.e., approximately $90 \%$ ) came from the sales of certified products. ${ }^{13}$ The labelling scheme covers almost exclusively food products. Besides coffee as a leading and most successful commodity, the Fair Trade certification portfolio covers a number of other major crops including bananas, cocoa and rice. The certification standards vary by commodity and production process (small-scale farming vs. production by hired labor) and distinguish between producers and traders.

In the case of coffee, traders have to trade directly with Fair Trade producers and:

1. pay at least a guaranteed minimum price (121 cents/lb for Arabica coffee) or above to cover the costs of sustainable production. In case the coffee price quoted at the New York Board of Trade exceeds the Fair Trade Minimum Price, the Fair Trade price equals the New York price,

2. pay the Fair Trade premium 10 cents that should be used by producers for community development or investment by individual producers,

3. offer pre-financing/liquidity up to $60 \%$ of the contract value,

4. sign contracts that promote long-term sustainable planning.

Fair Trade coffee producers, on the other hand, have to

1. be small-scale farmers associated in a democratic organization,

2. have the necessary export capacity,

\footnotetext{
${ }^{13}$ As FLO (2007) notes, the overall figure does not include non-labelled food products sold in Worldshops (i.e., smaller, locally based shops specializing in Fair Trade), nor does it include Fair Trade products offered through less common supply channels like mail orders or gift shops. Accounting for these figures most likely would not reverse the overall dominance of Fair Trade-certified sales.
} 
3. pursue environmentally friendly production techniques (FLO, 2007).

The most visible Fair Trade benefit to the participating farmers seems to be the Fair Trade Minimum Price. Shocks and long adjustment lags of inelastic supply and demand in the global coffee market directly translate into price fluctuations, which can inflict significant hardship on micro- and small-scale producers accounting for a significant part of the overall coffee production structure. ${ }^{14}$ These farms face limited opportunities to cope with adverse market developments especially in periods of prolonged low prices. The valuable case study by Bacon (2005) mentions measures both at the intensive and extensive margin that were taken by many non-participating farms during the past decade of coffee crisis. The measures at the intensive margin included crop diversification, ${ }^{15}$ increased labor input often coupled with the withdrawal of children from the education system, sharing resources through kinship networks, or increased reliance on barter. The micro-producers with minimal farmland had to search for labor on larger plantations in order to provide a living for their families. A qualitatively different, "extensive" form of farm household adaptation was migration.

Further evidence can be found in Raynolds (2002b, p. 417), who cites a Fair Trade farmer from the Mexican region Oaxaca:

"We have seen the prices paid to coffee growers in the region collapse. Everyone is leaving. We are able to keep producing because of the more favourable Fair Trade price. We are able to provide food and clothes for our families, even medicine. The children still attend school. We are not rich, but we are moving forward."

According to the estimates of the coffee growers in the Oaxaca region, Fair Trade farmers received close to three times higher income from the sales through the Fair Trade as opposed to conventional channels. Ronchi (2002) reports that over 1989-1995, the farmers from a Costa Rican Fair Trade cooperative SARAPIQUI received prices that were, on average, $39 \%$ higher than the those of the private middleman ("beneficio"), a local competitor to Fair Trade. Ronchi (2002, pp. 10-11) claims that

\footnotetext{
${ }^{14}$ In Central America, approximately $85 \%$ or 250,000 farms are micro- and small-scale (CEPAL (2002) cited in Bacon (2005)).

${ }^{15}$ The majority of farms maintain a strong subsistence ethic with coffee production serving as a primary source of cash income. Bacon (2005)'s surveys among Nicaraguan households observed that $61 \%$ of the interviewed farmers grew half or more of the food they ate, including corn, beans, bananas and other fruits. Surveyed farmers sold between $80-90 \%$ of their coffee harvest. The earned income reserved for off-farm purchases of food had been mostly spent on basic items such as salt, sugar, oil, and meat.
} 
"many of the farmers interviewed explicitly appreciate their continued participation in coffee whilst witnessing the disappearance of neighboring communities and the emigration of family members and acquaintances."

The importance of minimum Fair Trade prices during the times of coffee crisis has been emphasized also by Raynolds (2002) and Moore (2004). ${ }^{16}$ However, the availability of the minimum Fair Trade price during times of coffee gluts and low market prices might result in excess supply that forces FT farmers to sell part of their production via traditional channels. Depending on the relative prices and costs of their production on FT and regular markets, it is possible that the excess supply regime brings losses to some of the farmers. In Section 4, we develop a model that allows us to study these effects.

\subsection{Other benefits of Fair Trade}

The minimum Fair Trade price is not the only benefit to the participating farmers. The interviewed farmers often mention the advantages of stability rather than the actual level of the price. As a small-scale coffee producer in Costa Rica puts it:

"The prices before? They were worse - very bad! The price now is more sustainable - more fixed. A family can get ahead."(Ronchi. 2002)

An even more important dimension of Fair Trade, however, seems to be the access to developed markets as well as the expert assistance from Fair Trade organizations aimed to improve farmers' position on the market. Fair Trade cooperatives often perceive the scheme as an opportunity to learn about current demand trends and quality expectations by customers. Relationships between the cooperatives and ATOs usually exceed the notion of a common market transaction and can include joint investments or the development of marketing strategies for the developed market. Raynolds (2002b, p. 419) claims that

"in many cases the technical expertise and market information provided through Fair Trade may be more important for producer associations than the financial and commodity arrangements. ... This information is critical for those selling their coffee via conventional channels or seeking organic specification."

\footnotetext{
${ }^{16}$ Moreover, the feeling of security is further reinforced by the ability of pre-financing at interest rates typical in the developed countries (Raynolds, 2002).
} 
Ronchi (2002, p. 14) adds the experience of the Costa Rican Fair Trade cooperative Coocafé:

"The export department entirely credits the successful production of final products to the assistance received from ATOs. The experience has had a positive impact that is only inadequately described in financial terms. Producing for the final market had given them an important understanding of the full coffee marketing chain and hence allowed them to learn a great deal about a number of markets."

The elimination of middlemen and Coocafé's direct Fair Trade experience involved a great deal of learning as well as transmission of skills and in the end led to a markedly improved bargaining position vis-à-vis other market agents and official authorities. A similar experience had a Mexican cooperative ISMAM (Raynolds, 2002) and many other producers (FLO, 2007).

\section{Model}

While the farmers' narratives consistently report higher or at least stable incomes and improved living conditions due to the guaranteed Fair Trade price, the question still remains how the very existence of Fair Trade, the minimum price and other dimensions of the scheme impact upon non-participating producers. Fair Trade has been sometimes called a mechanism creating an excess supply of coffee, which ultimately hurts the non-participating farmers through a lower equilibrium price on the global market (The Economist, 2006). In this section we argue that regardless of the degree of competition on local coffee markets, the introduction of a Fair Trade market per se leads to an improvement or at worst a preservation of all farmers' incomes unless the total realized demand for both types of coffee decreases in a new equilibrium. ${ }^{17}$ In this respect, what many critics seem to address is not the actual existence of a market with Fair Tradecertified products but the effect of a guaranteed rather than market-determined Fair Trade price. This, together with Fair Trade's impact on middlemen's behavior and profits, is also a major focus of our study.

In this section we develop a model that allows for several transmission channels that might impinge on both participating and non-participating farmers. The model addresses the following questions: What is the impact of the introduction of Fair Trade

\footnotetext{
${ }^{17}$ The question how the demand for coffee changes when a FT market is introduced is primarily a question about the consumers' preferences. Since we could argue both for an increase as well as a decrease of the demand, we leave this question open.
} 
markets on farmers' incomes? Does the guaranteed Fair Trade price disadvantage those producers who do not engage in Fair Trade compared with those who do? How do the costs and benefits of the scheme depend on the structure of the markets?

For the sake of simplicity, we divide the exposition into two subsections. The opening subsection assumes the absence of middlemen with monopsonistic positions vis- 'a-vis the farmers. The basic setup presents a world describing two coexisting, perfectly competitive markets (one for conventional coffee, the other for Fair Trade coffee) supplied by farmers from regions. We first compare the two-market outcomes to the case with a single market for normal coffee and then examine the impact of the Fair Trade price set above its market-clearing level.

In the second part, we extend this framework by assuming market failure in the distribution chain. In this setup, the middlemen control access to consumers, purchase normal coffee from regional farmers and then deliver their product to the global market. Note that while the world without middlemen described in the opening subsection is a useful benchmark, it is not the existing structure of the coffee market. Our analysis thus allows us to compare the impact of the Fair Trade mechanism in markets that do have powerful middlemen with those that don't. It also allows us to predict what would happen if the role of middlemen were somehow eliminated. Would FT continue to operate if middlemen were absent?

\subsection{Fair Trade in a world without middlemen}

We assume there is a measure one of regions producing coffee and three types of economic agents: farmers producing coffee, consumers and the Fair Trade Organization (FTO). The FTO sets up a new market and decides on the contracting price $p^{F}$ at which the exchange will occur. The FTO does not engage in actual Fair Trade transactions and instead focuses purely on the institutional support of Fair Trade exchange. Assume each farmer decides between investment into the production of 1 unit of coffee or an outside option normalized to zero. ${ }^{18}$ Given that the farmer opted for coffee production, she can sell the harvested coffee on the world market with normal coffee and get $p$, or to the Fair Trade market at price $p^{F}$. In each region there is a measure one of farmers with heterogeneous production costs $c$ and compliance costs $f .{ }^{19}$ The production costs

\footnotetext{
${ }^{18}$ The normalization has been adopted for the sake of simplicity. While farmers might well face positive and possibly heterogenous outside options, these can be absorbed by the production cost parameter $c$. The parameter would then have to be rescaled and reinterpreted as net investment costs into coffee production.

${ }^{19}$ Given the absence of an intensive production margin, both types of farmers' costs are in principle fixed. We discuss their nature as well as the mutual relationship between $c$ and $f$ later in this section.
} 
$c$ follow a general distribution function with c.d.f. $G(c)$ defined over support $\langle 0,1\rangle$. All farmers can also enter the Fair Trade market, yet the cost of doing so for each farmer is $f$. We assume the following timing: ${ }^{20}$

1. The FTO sets up the FT market and sets the price $p^{F}$.

2. Farmers choose between no production (outside option), production of regular coffee, and production of certified FT coffee.

3. Production and trading take place.

The case for heterogeneity in production cost $c$ is rather straightforward. Farmers' education, experience, family size, equipment and soil fertility generally differ, which translates into corresponding differences in farm cost levels.

The relationship between production costs $c$ and compliance costs $f$ is less clear and derives directly from the nature of certification standards determined by the FLO. We argue that these costs are negatively correlated with farmers' productivity. To start with, the farmers willing to produce and sell under the FLO label have to be organized into cooperatives, keep records of all income and expenses and follow a number of other FLO monitoring guidelines. It seems quite reasonable to assume that the compliance with this kind of costs will be easier for more productive farmers whose lead in productivity presumably links to their superior management skills and expertise. The FLO's standards also include progress requirements in terms of growth or volume, again favoring those with higher productivity. Our emphasis on intangible skills such as knowhow and management capacity rather than production technologies in a traditional "narrow" sense likewise conforms to the anecdotal evidence. For example, Raynolds (2002b) mentions the case of a Mexican cooperative that succeeded in Fair Trade largely through its years of experience in conventional markets. Similarly, Weber (2007) reports the difficulties of younger, less experienced producer organizations with entering the Fair Trade markets while Raynolds (2002) emphasizes the necessary strong leadership and capacity to innovate.

A fraction of compliance costs $f$ can be attributed to the certification fees derived from the FLO's certification scheme. These take the form of a flat yearly fee paid to the FLO to cover the costs of certification and expenses related to on-site inspections. Note that the certification fee applies to the whole cooperative and thus introduces an incentive to expand in order to reduce the per-capita certification cost. Since the

\footnotetext{
${ }^{20}$ We focus on subgame perfect equilibria, in which all players correctly expect those variables that are determined later in the game. For example, farmers correctly expect the price of coffee on the world market, $p$.
} 
incentives at the cooperative level lie outside the primary focus of our paper, we abstract from this issue and assume the per capita certification fee to be fixed so that the positive correlation between production costs $c$ and overall compliance costs $f$ will be preserved.

In addition to the positive correlation between the two types of costs, we assume that the compliance costs are indivisible. That is, farmers cannot choose to incur only a part of the compliance costs $f$, depending on the proportion of their harvest targeted to the Fair Trade market. Given that the above-mentioned compliance costs relate largely to farm attributes that are indivisible in nature, we believe our assumption to be a reasonable one.

As far as the other assumptions, the introduction of multiple regions reflects the fact that coffee growing areas are typically spatially divided among private middlemen taking a monopsonist or oligopsonist position with respect to local farmers. Arbitrage among regions is in practice limited given the lack of information, poor infrastructure and natural barriers in mountainous areas where many small-scale coffee producers live (see e.g. Ronchi, 2002). ${ }^{21}$ We also do not allow for production adjustment at the intensive margin and instead assume a fixed output per farmer. As Weber (2007) observes, FLO generally does not induce a higher Fair Trade supply of presently participating farmers and instead re-channels the existing production from conventional markets either through the certification of additional applicants. Even if this was not the case, however, the situation of farmers often does not permit a significant expansion of output due to either the absence of key productive assets such as land or capital, or the replacement of the former coffee growing areas by urban development (Ronchi 2002; Winters et al. 2004). This fact has also been acknowledged by the European Fair Trade Association, which stated that "given the parcels of land [the farmers] possess and the lack of working capital and resources, [the expansion of output] is almost out of the question" (EFTA (1998) cited in Ronchi (2002)). Despite the suggestive evidence on its relatively low relevance for farmers' adjustment, the model can nonetheless allow for the intensive margin. The impact of price changes on the numbers of active farmers would then be partly muted via the accommodation of farm output, yet the middlemen's incentives

\footnotetext{
${ }^{21}$ The normalization of the number of regions to 1 has been used for ease of exposition. Note that this does not impact the results. The interested reader may simply multiply demand functions by $\frac{1}{n}$ (where $n$ stands for the number of regions) and proceed with the analysis. Similarly, one might argue that the distribution of the Fair Trade production across regions is not symmetric. Allowing for a fraction of regions to be without Fair Trade production (yet with the same assumed cost structure) would impact on the relative strength of individual channels at work. The qualitative picture, however, would not change. Finally, one might argue that the cost structure is not identical across regions. In such a case, the model might be given an alternative interpretation, where the overall cost distribution across internally homogeneous regions follows c.d.f. $G(c)$ and a single middleman with sole access to world markets decides on the overall amount of purchases. The assumption of the middleman being a price taker on world markets, however, would be rather difficult to justify.
} 
would remain the same, since the middleman is primarily interested in the available quantity of coffee instead of the number of farmers. The FTO, on the other hand, would have a lower or entirely lacking capacity to increase farmers' participation through the minimum contracting price $p^{F}$ and as a result, there would be less or no justification at all for its minimum price policy.

\subsubsection{The farmers' constraints}

In our model, a farmer has three options. Given her expectations regarding the price of regular coffee $p$, she can take an outside option of zero value (no production), or invest into 1 unit of coffee production. Given her decision to invest, she can sell to the market with normal coffee or pay for the FT standards at an additional cost $f$ and sell on the FT market. The participation constraints are

no production: $\quad p<c \& \pi p^{F}+(1-\pi) p-c<f$

sell regular coffee: $\quad p \geq c \& \pi\left(p^{F}-p\right)<f$ sell FT: $\quad \pi p^{F}+(1-\pi) p-c \geq f \& \pi\left(p^{F}-p\right)>f$,

where $\pi=1$ corresponds to the situation with both markets clearing. ${ }^{22}$

If $\pi<1$, the Fair Trade price $p^{F}$ is set above its market-clearing level. As a result, excess supply on the FT market makes the participating farmers sell only part of their production through the Fair Trade channel, the rest being directed back to markets with normal coffee. In the rational expectations equilibrium, the expectations will have to coincide with the realized proportion of the total FT output sold to FT customers.

The excess supply with $\pi<1$ is a fairly justified assumption, both theoretically and empirically. First, it is usual to see excess supply on a market in which the price is artificially increased above its equilibrium value. Empirical studies confirm this expectation. According to Bacon (2005), close to $70 \%$ of Fair Trade cooperatives' production goes to conventional coffee markets and this figure is attributed to low demand and high quality requirements. The Costa Rican cooperatives examined by Ronchi (2002) sold a mere $49 \%$ of their coffee production as Fair Trade. In 2002, the FLO had to temporarily reject pending applicants due to the discrepancy between supply and demand. In the same year the FLO estimated that the supply of Fair Trade coffee was seven times the total Fair Trade volume actually exported (Weber, 2007). While there are other possible explanations why FT farmers might sell their coffee through conventional

\footnotetext{
${ }^{22}$ In general, expectations might depend on some characteristics of the farmer (e.g., knowledge of the FT market, size of the farm or experience with coffee production). For simplicity, we abstract from these considerations.
} 
markets (e.g, liquidity problems during the harvest season (Bacon, 2005)), in light of the above-mentioned evidence it seems that excess supply plays an important role. In our model, the assumption of FT sales flowing partially through conventional channels relies fully on the excess supply argument.

The above-mentioned constraints define the potential combinations of $c$ and $f$ (as well as the corresponding cut-off points) that are consistent with the particular participation choices of the farmers. For simplicity, we will assume $f=k c$, where $k \leq 1$ is a parameter. ${ }^{23}$ Figure 1 illustrates the participation constraints and the respective supplies for normal and FT coffee generated by the line $f=k c$ with $k=1$ and $c$ distributed uniformly over $\langle 0,1\rangle$.

\subsubsection{Objective function of the Fair Trade Organization}

The Fair Trade Organization is a non-profit institution that claims to aim to improve the living conditions of farmers. It is not clear how this broadly defined motivation translates into a decision about the Fair Trade price and other requirements. Thus, instead of making an explicit assumption about the objective function of the FTO, we study how different choices of the Fair Trade price impacts farmers (both participating and nonparticipating). This allows us to discuss which objective of the FTO is consistent with its current behavior and which is not.

Regardless of the objective function of the FTO, its role as a certification body is to guarantee to the consumer that certain conditions (like price, pre-financing, etc.) for the farmers are met. In this respect, the FT certification works like any other certification system. The certifier, FTO, assures consumers about the properties of the good they purchase that they cannot directly or easily observe. Thus, it solves the asymmetry of information problem and facilitates the matching between farmers' supply and consumer preferences. The FTO, however, does not enter into direct transactions with either farmers or traders.

\footnotetext{
${ }^{23}$ Our specific assumption of the linear relationship between production costs $c$ and compliance costs $f$ satisfies the assumption of a positive correlation between $c$ and $f$ and greatly simplifies the subsequent analysis. We might further allow for a part of compliance costs to reflect the fixed per-capita certification fee discussed in this section, so that $f=a+k c, a>0$. Nonetheless, the positive constant $a$ does not add much to our story (see the curve $f=k c$ in Figure 1, which is in fact a special case of $f=a+k c$ with $a=0$ ). Also note that independent of the production $\operatorname{costs} c$ and given the coffee prices $p$ and $p^{F}$, if $k=0$ and $f=a$, all active farmers would be willing to participate either exclusively in the Fair Trade or the normal market. The price mechanism would then have to adjust so that ultimately the farmers are indifferent between the two choices. Hence some heterogeneity in $f$ is needed for the model to become interesting.
} 


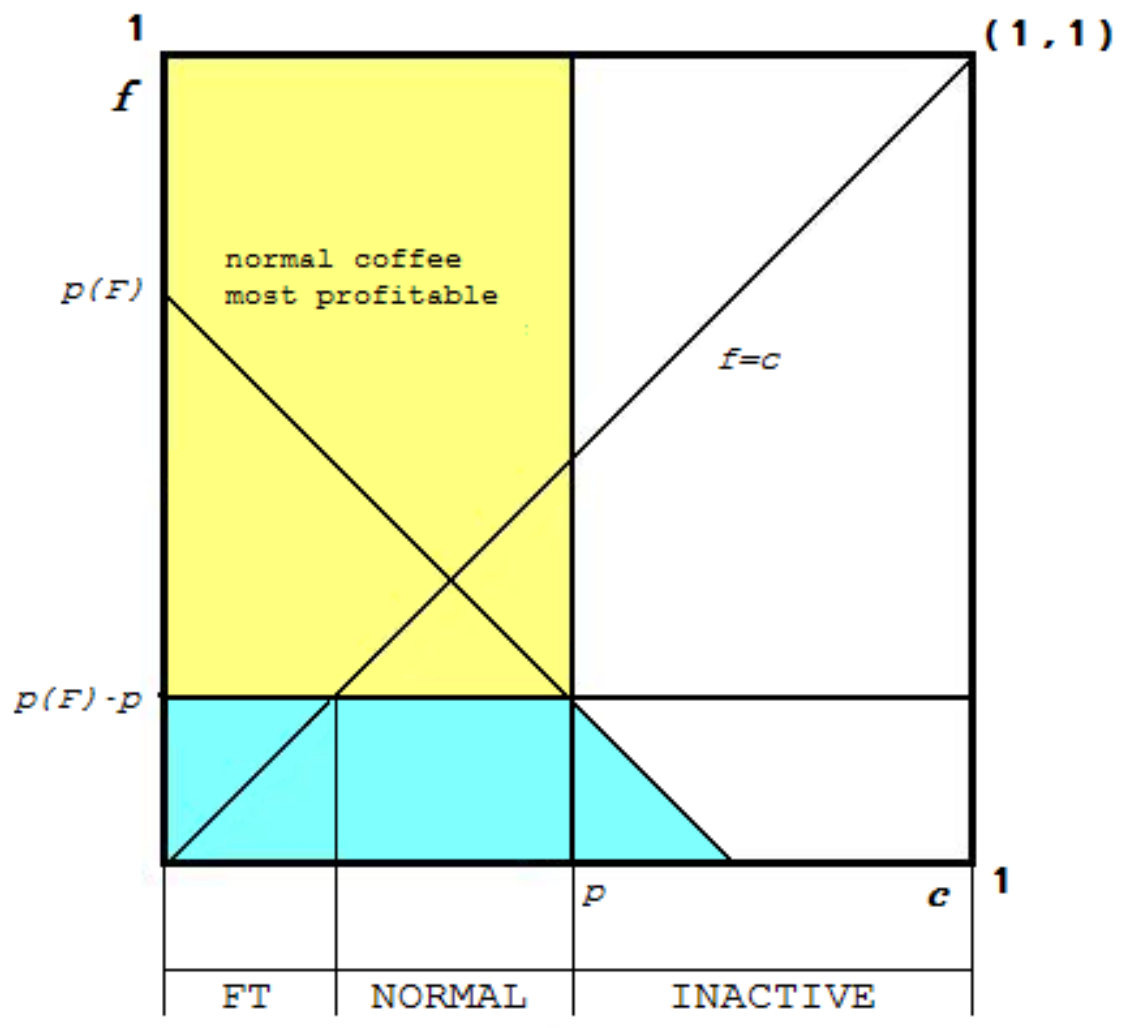

Figure 1: Farmers' decisions for various cost combinations $(f, c)$. 
It is easy to find examples of for-profit certification systems but it seems that the for-profit behavior of the FTO would go directly against what it tries to sell. Thus, we focus on possible non-profit objectives instead. It is also important to note that the quality that the certifier FTO provides is not the taste of the coffee and thus Fair Trade complements rather then subsitutes vertical differentiation in this respect. Fair Trade certification, even though it requires the sustainability of production processes, does not require that the products are organic. In fact, one can often find both organic and Fair Trade certification of the same coffee.

\subsubsection{The equilibrium and comparative statics}

We will assume that world demand for FT coffee $D^{F}\left(p, p^{F}\right)$ depends on the prices of both types of coffee and satisfies the following restrictions: ${ }^{24}$

$$
D_{p}^{F}\left(p, p^{F}\right)>0, D_{p^{F}}^{F}\left(p, p^{F}\right)<0 \text { and }\left|D_{p}^{F}\left(p, p^{F}\right)\right|<\left|D_{p^{F}}^{F}\left(p, p^{F}\right)\right|
$$

A symmetric pattern is required to hold for normal coffee demand $D^{N}\left(p, p^{F}\right)$. These assumptions impose reasonable restrictions - the direct price effect is negative and the indirect price effect is positive but smaller in absolute value than the direct effect.

Note that given the minor share of Fair Trade in world coffee consumption (see Section 2), the cross-price effects impacting upon the non-participating farmers could arguably be rather tame (if there are any). In practice, however, even world demand differentiates across regions of origin. As a result, Fair Trade production in e.g. Nicaragua, where the share of Fair Trade production is relatively high, might indeed affect the prices of Nicaraguan coffee. We assume that Fair Trade is strong enough to shift world prices. ${ }^{25}$

We are interested in an equilibrium with both markets being active.

If the price $p^{F}$ becomes market-determined, participation and realized supplies coincide as farmers supply either to the normal or FT coffee market and $\pi=1$. In the

\footnotetext{
${ }^{24}$ Several studies such as e.g., Broda and Weinstein (2006), Petrin (2002), or Feenstra (1994) addressed the welfare impact of the introduction of new goods/markets within the Dixit and Stiglitz (1977)'s framework that relies largely on CES utility functions and love-of-variety. In the present context of market creation through environmental or socially conscious labelling, Podhorsky (2006) provides an extension of Melitz (2003)'s industry model with heterogeneous firms where each firm produces a different variety and decides on the adoption of environmental label. For Fair Trade labelling, however, the goods in question are typically ex ante homogeneous (such as locally fragmented coffee production before the introduction of FT) and hence cannot be modelled as a differentiated variety demanded by CES customers. By so doing, it imposes product differentiation among firms/farmers before the actual introduction of Fair Trade.

${ }^{25}$ In the Appendix we also provide a model extension in which we assume that the price of FT coffee does not impact the demand for regular coffee.
} 
excess supply setup with $\pi<1$, however, we need to distinguish between the local participation choices and the realized supplies to global markets.

$$
\begin{aligned}
\text { [Participation in FT] }: & S^{F}=G\left(\frac{\pi\left(p^{F}-p\right)}{k}\right) \\
{[\text { Participation in N] }:} & S^{N}=G(p)-G\left(\frac{\pi\left(p^{F}-p\right)}{k}\right) \\
{[\text { Realized FT] }:} & S^{W F}=\pi S^{F} \\
{[\text { Realized N] }:} & S^{W N}=S^{N}+(1-\pi) S^{F},
\end{aligned}
$$

where N stands for "normal/regular coffee market" and FT for "Fair Trade market". While $G\left(\frac{\pi\left(p^{F}-p\right)}{k}\right)$ of the total population of farmers choose to participate in the FT scheme, they are not able to sell exclusively to FT markets. Not being able to find enough buyers, their remaining harvest $(1-\pi) S^{F}$ has to be sold through conventional channels.

In the rational expectations equilibrium, the realized supplies and demands have to be equal.

$$
\begin{gathered}
\pi S^{F}\left(\pi, p, p^{F}\right)=D^{F}\left(p, p^{F}\right) \\
S^{N}\left(\pi, p, p^{F}\right)+(1-\pi) S^{F}\left(\pi, p, p^{F}\right)=D^{N}\left(p, p^{F}\right) . \\
\pi=\pi\left(p^{F}\right), p=p\left(p^{F}\right)
\end{gathered}
$$

It is possible to show that there exists an equilibrium under standard conditions, using the Implicit Function Theorem (IFT). The assumptions of the IFT require the existence of a solution in one point, and non-singularity of the Jacobian of the equilibrium conditions. This in fact imposes mild conditions on the supply and demand functions. The existence of an equilibrium is not the prime focus of our paper and we thus do not provide a detailed proof. A numerical example later shows that some equilibria indeed exist. Furthermore, in the Appendix we discuss informally the existence of equilibria in a model with middlemen.

Lemma 1 Under standard conditions on supply and demand functions, there exists an equilibrium for a range of FT prices $p^{F}$.

The following lemma shows that the presence of Fair Trade in our model benefits all farmers under quite general conditions. 
Lemma 2 Given that markets clear (i.e., $\pi=1$ ), the incomes of all farmers (weakly) increase if and only if the total realized demand does not fall after the introduction of the Fair Trade market.

Proof. If the overall realized demand in a new Fair Trade equilibrium remains constant, it can exist only if the participating farmers are relatively better off than selling through the conventional channels. The normal farmers' payoffs are furthermore unchanged due to a constant price $p$.

If the overall realized demand in a new Fair Trade equilibrium increases, the nonparticipating farmers have to be better off since the actual increase only becomes possible if the previously inactive farmers enter the production and this can only happen once the purchase price of normal coffee $p$ rises. Furthermore, the participating farmers are unambiguously better off using the same argument as in the case of a small Fair Trade market.

If the total realized demand declines following the introduction of Fair Trade, the fall in the consumption of conventional coffee has been less than compensated by the purchases of Fair Trade coffee. As a result, normal farmers become worse off.

In other words, unless total realized demand does not fall after the introduction of the Fair Trade market, the very introduction of the scheme by the Fair Trade Organization absent any price-setting constraints helps the participating farmers and at least does not hurt the incomes and participation of normal coffee producers. Figure 2 illustrates the case where the total realized demand has increased after the introduction of Fair Trade despite a shift away from normal coffee. This happened due to a more-thancompensating rise of Fair Trade consumption.

Assuming that the equilibrium exists, we are now interested in how it compares with the market-clearing equilibrium at which there is no excess supply on the FT market $(\pi=1)$.

Lemma 3 If there are no middlemen, an increase in price $p^{F}$ above its market-clearing level increases the excess supply $(1-\pi)$ and reduces the price of regular coffee $p$.

$$
\frac{d \pi}{d p^{F}}<0, \frac{d p}{d p^{F}}<0
$$

All proofs are provided in the Appendix, unless noted otherwise. 

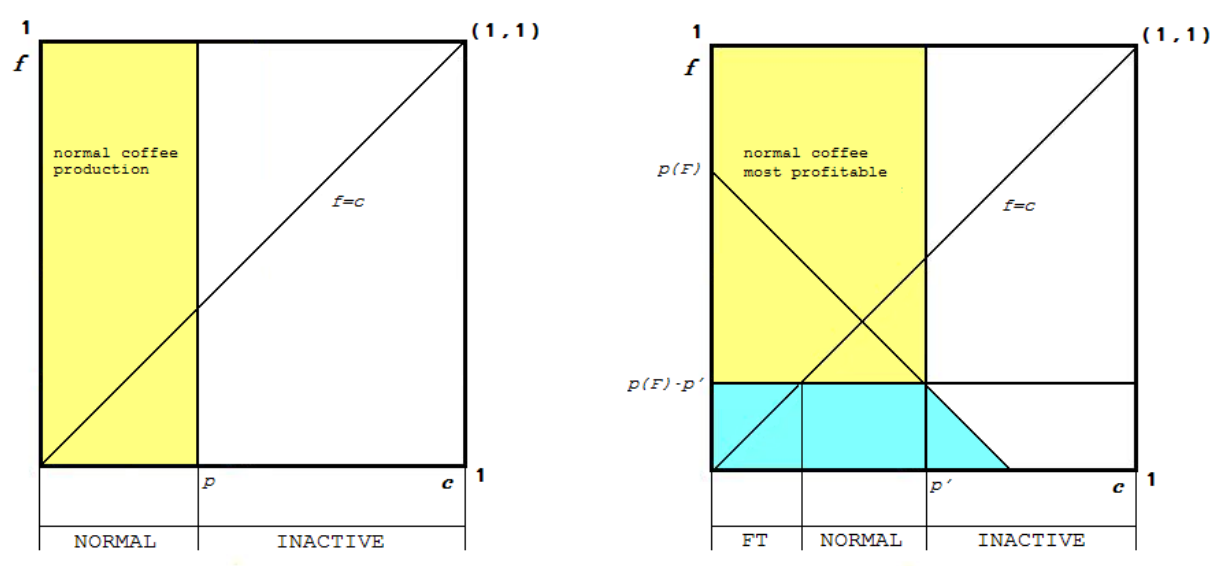

Figure 2: Shift away from normal coffee when Fair Trade is introduced (total demand increases)

Lemma 4 By increasing the price $p^{F}$ above its market-clearing level, the farmers' participation in the Fair Trade scheme increases if and only if

$$
\left|\varepsilon_{p^{F}}^{D^{N}} \frac{S^{W N}}{S^{W F}}\right|<\left|\varepsilon_{p^{F}}^{\pi}\right| \text { and }\left|\varepsilon_{p^{F}}^{D^{F}}\right|<\left|\varepsilon_{p^{F}}^{\pi}\right|
$$

The payoffs of farmers participating in Fair Trade decrease unambiguously relative to the market-clearing case.

The intuition behind both lemmas is quite straightforward. Holding other things constant, if the Fair Trade Organization sets the contracting price $p^{F}$ above its marketclearing level so as to maximize farmers' participation in Fair Trade, the demand for Fair Trade has to fall. Despite the concomitant rise of the demand for conventional coffee (we assume that the indirect price effect is weaker than the direct one), the excess supply of coffee remains preserved and translates into corresponding pressure to reduce the price $p$. Furthermore, if the demand elasticities are low vis-à-vis excess-supply elasticity $\varepsilon_{p^{F}}^{\pi},{ }^{26}$ the decrease in price $p$ becomes so pronounced that it makes the Fair Trade scheme more attractive and thus increases participation. In such a situation the effects of the minimum price $p^{F}$ resemble the impact of the minimum wage in labor markets with heterogenous oligopsonists (Manning (2003)). While the actual mechanism at work varies in each case, both results point to the importance of agent heterogeneity in the modelling of market interventions. This result has a simple corollary.

Corollary 5 In the excess-supply equilibrium with $\pi<1$, the participation in the Fair

\footnotetext{
${ }^{26}$ The excess-supply elasticity $\varepsilon_{p^{F}}^{\pi}$ is defined as $\frac{p^{F}}{\pi} \frac{d \pi}{d p^{F}}$.
} 
Trade scheme can increase relative to the market-clearing case with $\pi=1$. This might happen despite the fall of the participating farmers' payoffs.

Increasing the price $p^{F}$ above its market-clearing level hurts all farmers regardless of their status, since both the price of the regular coffee $p$ and the probability of being able to sell Fair Trade $\pi$ more than offsets the initial benefit of a higher FT price $p^{F}$. The previous result holds even if participation in the Fair Trade scheme actually rises. The FT market then becomes relatively more attractive than the regular market, yet the FT payoffs of the switching farmers fall short of the normal-coffee payoffs earned in the market-clearing equilibrium. Had this not been the case, the switching farmers would have acted irrationally in the first place by having chosen normal coffee production in the market-clearing equilibrium.

Nonetheless, given the positive impact of the introduction of the Fair Trade market and monotonically decreasing farmers' payoffs, the FT farmers are still better off as compared to the setup with the non-existent Fair Trade market. To see this, note that if the Fair Trade price $p^{F}$ were gradually raised up to the level prohibiting the existence of the Fair Trade market, all farmers would supply to the normal market, thus imitating the equilibrium with a single existing market for normal coffee.

In the following, we move away from the analysis of farmers' individual payoffs and instead explore the impact of the excess-supply price $p^{F}$ both on the aggregated profits of all farmers and on Fair Trade participants only. The aggregated profits serve as a proxy for resources available for community investment. ${ }^{27}$

Lemma 6 In the excess-supply equilibrium with $\pi<1$, the aggregated profits of all farmers are decreasing.

The fact that the total profit of all farmers is decreasing in $p^{F}$ does not tell us whether it is because the profits of both Fair Trade and regular farmers decrease, or because one group benefits in the aggregate while the other does not. The following lemma partially answers this question. It formalizes the intuition that Fair Trade farmers cannot benefit in aggregate if their participation decreases as a result of an increase in price $p^{F}$. Note that the lemma actually strengthens this result by showing that even an increase in participation may not be sufficient to guarantee an increase in their profits.

\footnotetext{
${ }^{27}$ The literature on Fair Trade lists a number of benefits of Fair Trade that the present framework addresses only indirectly or not at all (for a brief outline and references see the Appendix). One of the frequently mentioned improvements concerns the pooling of resources for the production of positive externalities. Ronchi (2002) reports the efforts of the Costa Rican cooperative COOPELDOS aimed at the maintenance of local roads, other cooperatives provide a number of services such as extended credit or reforestation support also to non-members. Strong rural linkages operating through large expenditure shares of local non-tradeables (e.g., perishable and/or locally processed foods and services) have been emphasized in a study by Winters et al. (2004).
} 
Lemma 7 If the participation of Fair Trade farmers decreases as a result of an increase in $p^{F}$, then the overall Fair Trade farmers' profit decreases.

The observation is straightforward, since we already know that an increase in $p^{F}$ above its market-clearing level lowers the profits of Fair Trade farmers. ${ }^{28}$ The only theoretical possibility thus remains the case when the participation in Fair Trade increases. However, such a condition is not sufficient given the simultaneous fall of Fair Trade farmers' individual profits (see the Appendix). We will return to the possibility of increased overall Fair Trade profits (driven by participation) in the following section with middlemen.

\subsubsection{Summary of the results in the world without middlemen}

In this section we focused on the effect of the introduction of a Fair Trade market and a binding minimum price $p^{F}$ in a setup without the presence of monopsonistic middlemen. Our interim results assign a generally positive role to Fair Trade in that setting up a new market might improve the matching of consumers' preferences with farmers' supply. On the other hand, the results conform to the critiques expressed e.g. in The Economist (2006) or the Washington Post (2005), claiming that the excess supply caused by the binding minimum price policy of the FLO tends to depress the incomes of the nonparticipating farmers. This happens through the decline in the normal coffee price $p$, which in addition forces some of the most disadvantaged to leave coffee production and seek outside options. In this respect the Fair Trade scheme does not help farmers as much as it potentially could, which also translates into profits at the aggregate level. Nonetheless, we assert that once the new Fair Trade market per se boosts the farmers' incomes, the excess-supply regime still outperforms the initial situation with a single market for normal coffee.

In the following section we allow for a specific kind of market failure on the normal coffee market and incorporate monopsonistic middlemen restricting the access to world markets. We will focus on the relationship between Fair Trade, farmers' and middlemen's incomes and the behavior of the normal coffee price $p$.

\subsection{Fair Trade in a world with middlemen}

Previous sections have dealt with two interconnected markets absent any intermediaries. The middlemen, however, play a significant role in the overall distribution chain and

\footnotetext{
${ }^{28}$ In the absence of quantity adjustment at the farmer's individual level, payoffs and profits can be used interchangeably.
} 
their allegedly exploitative position in fact stood at the very roots of the whole Fair Trade movement (see previous sections). For these reasons we extend the model to allow for the presence of intermediaries. These middlemen purchase coffee from local farmers and they have sole access to world markets.

1. FTO sets price $p^{F}$.

2. Middlemen set price $p^{M}$.

3. Farmers choose between no production, regular coffee production and FT coffee production.

4. Production and trade take place.

We assume that such a middleman is small with respect to global markets, yet she holds some monopsony power vis-à-vis the farmers. ${ }^{29}$ Farmers' choices are identical to those from the previous market-clearing case, yet now instead of the global market price $p$ they receive a price $p^{M}$ offered by the middleman. We assume farmers have expectations about the probability $\pi$ of being able to sell their production on the FT market. The case $\pi=1$ corresponds to no excess supply, while if $\pi<1$ there is excess supply.

\subsubsection{The middleman's problem}

Each middleman maximizes her profit so that

$$
\begin{array}{r}
\max _{p^{M}}\left(p-p^{M}\right)\left[S^{N}+(1-\pi) S^{F}\right] \\
\text { s.t. } S^{N}=G\left(p^{M}\right)-G\left(\frac{\pi\left(p^{F}-p^{M}\right)}{k}\right) \\
S^{F}=G\left(\frac{\pi\left(p^{F}-p^{M}\right)}{k}\right),
\end{array}
$$

which for a given $\pi$ leads to the first order condition defining an implicit solution for $p^{M}$.

$$
\left[p^{M}\right]:-\left[S^{N}+(1-\pi) S^{F}\right]+\left(p-p^{M}\right)\left(g\left(p^{M}\right)+\frac{\pi^{2}}{k} g\left(\frac{\pi\left(p^{F}-p^{M}\right)}{k}\right)\right)=0
$$

\footnotetext{
${ }^{29}$ Our timing also requires that the middlemen can commit to a given price and to buy any amount of coffee from farmers at that price. The second restriction is not binding because in rational expectations equilibrium, middlemen correctly expect the amount of coffee supplied by the farmers.
} 
or alternatively,

$$
\left(p-p^{M}\right)\left(g\left(p^{M}\right)+\frac{\pi^{2}}{k} g\left(\frac{\pi\left(p^{F}-p^{M}\right)}{k}\right)\right)=G\left(p^{M}\right)-\pi G\left(\frac{\pi\left(p^{F}-p^{M}\right)}{k}\right) .
$$

One can immediately observe that the middleman's optimal price $p^{M}$ is a function of the success rate of Fair Trade farmers $\pi$, the price of the Fair Trade coffee $p^{F}$, and the price $p$ the middleman receives on the world market with conventional coffee. The following lemma summarizes the relationship between the purchase price $p^{M}$ and the above-mentioned variables.

Lemma 8 The middleman's optimal price $p^{M}$ is an increasing function of all its arguments, i.e., $\frac{\partial p^{M}}{\partial \pi}>0, \frac{\partial p^{M}}{\partial p^{F}}>0$, and $\frac{\partial p^{M}}{\partial p}>0$.

Proof. We provide an intuition for this statement; the formal proof is standard. An increase in the success rate $\pi$ or the Fair Trade price $p^{F}$ might make the middleman lose part of the available farmers' supply. In response to this, the middleman partly compensates farmers by raising her purchase price $p^{M}$. Similarly, a higher selling price $p$ boosts the middleman's revenues and allows further adjustment on the cost side.

More formally, the middleman sets the optimal price $p^{M}$ so as to equate the two expressions. If $\pi, p^{F}$, or $p$ increases, the marginal revenue loss for a given $p^{M}$ increases, while the marginal cost savings fall or remain unchanged. Since the marginal gains in revenues from additional normal coffee purchases exceed the corresponding marginal costs if $p^{M}$ is relaxed, it is optimal ${ }^{30}$ for the middleman to raise the purchase price to $p^{M \prime}$ in order to compensate for the improved outside options of the farmers (upward shifts in $\pi$ and/or $p^{F}$ ) or to exploit favorable conditions on world markets (higher $p$ ).

One can also note that the middleman's optimal price setting means that any market developments reflected in price $p$ translate only indirectly and typically in a less pronounced way into farmers' revenues. ${ }^{31}$

\subsubsection{The equilibrium and comparative statics}

We start with an analysis of the equilibrium where the FTO decides on a price regime $p^{F}$ when the middleman is present. If the participating farmers sell only part of their

\footnotetext{
${ }^{30}$ The second order condition implies that the slope of the marginal cost-savings function is steeper than the slope of the marginal revenue loss function. As a result, the equality can be restored only at a higher price $p^{M}$.

${ }^{31}$ One can conjecture that in most cases $\frac{\partial p^{M}}{\partial p}<1$, but the proof depends on the behavior of the derivative of density function $g^{\prime}$. Thus, there might exist an equilibrium in which even $\frac{\partial p^{M}}{\partial p}>1$. For uniform distribution, one can easily show that $\frac{\partial p^{M}}{\partial p}=\frac{1}{2}$.
} 
production through the Fair Trade channel, the rest is sold to the middleman.

The farmer's choices change to:

no production: $p^{M}<c \&\left[\pi p^{F}+(1-\pi) p^{M}\right]-c<f$,

sell to middleman: $\quad p^{M} \geq c \& \pi\left(p^{F}-p^{M}\right)<f$,

sell FT: $\left[\pi p^{F}+(1-\pi) p^{M}\right]-c \geq f \& \pi\left(p^{F}-p^{M}\right) \geq f$,

where $p^{M}$ is the middleman's optimal price, taking into account part of the Fair Trade production that could not match Fair Trade markets. As before, we restrict our attention to the case $c=k f$. Similar to the previous case when the middleman is not present, one has to distinguish between farmers' local participation choices and the realized supplies.

We have

$$
\begin{aligned}
\text { [Participation in FT] }: & S^{F}=G\left(\frac{\pi\left(p^{F}-p^{M}\right)}{k}\right), \\
\text { [Participation in N] }: & S^{N}=G\left(p^{M}\right)-G\left(\frac{\pi\left(p^{F}-p^{M}\right)}{k}\right), \\
\text { [Realized FT] }: & S^{W F}=\pi S^{F}, \\
{[\text { Realized N] }:} & S^{W N}=S^{N}+(1-\pi) S^{F} .
\end{aligned}
$$

In a rational expectations equilibrium the realized supplies and the realized demands are equal.

$$
\begin{gathered}
S^{W F}=\pi S^{F}\left(\pi, p^{M}, p^{F}\right)=D^{F}\left(p, p^{F}\right) \\
S^{W N}=S^{N}\left(\pi, p^{M}, p^{F}\right)+(1-\pi) S^{F}\left(\pi, p^{M}, p^{F}\right)=D^{N}\left(p, p^{F}\right) . \\
\pi=\pi\left(p^{F}\right), p=p\left(p^{F}\right), p^{M}=p^{M}\left(\pi, p, p^{F}\right)
\end{gathered}
$$

Lemma 9 Given that markets clear (i.e., $\pi=1$ ), all farmers are better-off if and only if the price $p^{M}$ offered by the middlemen increases once the FT market opens. This happens either if the downward adjustment of the world normal coffee price p stays relatively modest, or if the price $p$ actually increases in response to the new FT market.

The statement of the preceding lemma conforms to our results from Lemma 2 that dealt with the world without middlemen. In fact, the present results are slightly stronger than those from Lemma 2. The reason is that contrary to the case without middlemen, the non-participating farmers now fare strictly better even if the price of normal coffee 
remains unchanged. This happens as a consequence of the strategic behavior of the middleman, who finds it profitable to adjust her price $p^{M}$ slightly so as to mute the outflow of farmers towards Fair Trade. A direct consequence of the middleman's behavior is also that the non-participating farmers can be better off even if the normal coffee price $p$ falls, given that the effect of a decline in price $p$ does not outweigh the positive effect of Fair Trade farmers' improved access to world markets.

Moving to the comparative statics, we are now interested in how the price of normal coffee $p$ changes once the FTO sets price $p^{F}$ above its market-clearing level (i.e., $\pi<1$ ).

Lemma 10 Assume that $\frac{\partial p^{M}}{\partial \pi}>0$ is small enough. In the presence of middlemen, an increase in price $p^{F}$ above its market-clearing level increases the excess supply $(1-\pi)$ and might reduce or increase the price of regular coffee $p$.

Increasing $p^{F}$ above the market-clearing level might lead to four possible responses of $p$ and $\pi$,

$$
\begin{aligned}
& \frac{d p}{d p^{F}}<0, \text { and } \frac{d \pi}{d p^{F}}<0 ; \frac{d p}{d p^{F}}>0, \text { and } \frac{d \pi}{d p^{F}}>0 \\
& \frac{d p}{d p^{F}}>0, \text { and } \frac{d \pi}{d p^{F}}<0 ; \frac{d p}{d p^{F}}<0, \text { and } \frac{d \pi}{d p^{F}}>0
\end{aligned}
$$

The combination

$$
\frac{d p}{d p^{F}}<0, \text { and } \frac{d \pi}{d p^{F}}>0
$$

is not possible. Technically possible, yet very unlikely, is the case

$$
\frac{d p}{d p^{F}}>0, \text { and } \frac{d \pi}{d p^{F}}>0
$$

First of all, an increase in $\pi$ following the departure from market clearing is not a viable option given that $\pi=1$ and $\pi \in\langle 0,1\rangle$. Secondly, while further away from the market-clearing price $p^{F}$ such a constellation might still be permissible, this can happen only if one is willing to accept $\frac{d D^{F}\left(p, p^{F}\right)}{d p^{F}}>0 .{ }^{32}$ We do not find such an adjustment setting plausible and instead focus on the remaining options. Thus, there are only two

\footnotetext{
${ }^{32}$ The following lemma states that $\frac{d p^{M}}{d p^{F}}<0$, which together with the present possibility that $\frac{d \pi}{d p^{F}}>0$ implies $\frac{d S^{F}}{d p^{F}}>0$. But then the realized Fair Trade demand $D^{F}$ has to increase even more than Fair Trade supply $S^{F}$ in the new equilibrium in order to be consistent with $\frac{d \pi}{d p^{F}}>0$.
} 
interesting cases where an increase in $p^{F}$ raises the excess supply

$$
\begin{aligned}
& \frac{d p}{d p^{F}}<0, \text { and } \frac{d \pi}{d p^{F}}<0, \\
& \frac{d p}{d p^{F}}>0, \text { and } \frac{d \pi}{d p^{F}}<0 .
\end{aligned}
$$

Note that the results from the previous lemma differ markedly from the setup with no middlemen and contradict the statements by The Economist (2006) regarding the declining normal coffee prices in the excess-supply regime. Given that an excess supply of Fair Trade coffee is indeed able to influence the prices of regular coffee, these can in principle move in both directions. In particular, the arguments relying on the price mechanism operating through world markets do not take into account the presence of market failure in the distribution chain. The introduction of the Fair Trade channel mitigates the negative impact of the middlemen restricting coffee supplies. The Fair Trade excess-supply regime, on the other hand, returns part of the market power back to the middlemen, reintroduces previous inefficiency and in some cases might even lead to an actual increase in the prices of regular coffee. Within the discussion of the excesssupply's impact on the incomes of farmers, nonetheless, our results conform to The Economist (2006)'s critique.

Lemma 11 In the excess-supply equilibrium with $\pi<1$, the non-participating farmers are unambiguously worse off relative to the situation with the market-clearing Fair Trade scheme $(\pi=1)$. In other words, $\frac{d p^{M}}{d p^{F}}<0$.

If $\frac{d p}{d p^{F}}>0$, the overall demand falls unambiguously given our demand assumptions and hence $\frac{d p^{M}}{d p^{F}}<0$ in order to have a viable equilibrium. If $\frac{d p}{d p^{F}}<0$, we show that it still holds that $\frac{d p^{M}}{d p^{F}}<0$, otherwise the monopsonist does not behave optimally.

Consider the situation of an increased price $p^{F}$. Given that price $p^{F}$ rises and holding price $p$ constant, the demand for Fair Trade falls, so the part of production previously sold as Fair Trade needs to be sold via middlemen to normal markets. Given $p^{M}$ and $p$ and regardless of farmers' participation choices, the middlemen now face a higher supply from farmers and can adjust optimally. Increasing $p^{M}$ given $p$ would decrease their profits even if one ignores the unexpected windfall coming from FT. The reason is that in such a case the middlemen would not have been optimizing ex ante in the first place. Taking into account the windfall would make their decision even more unprofitable at the margin. So the middlemen will adjust by decreasing the purchase price $p^{M}$.

Similarly to the setup without middlemen, we explore the impact of the excess-supply price $p^{F}$ both on the aggregated profits of all farmers and on Fair Trade participants 
only.

Lemma 12 If $\pi<1, \frac{d \pi}{d p^{F}}<0$, and $\frac{d p^{M}}{d p^{F}}<0$ in an equilibrium, then the revenue of all farmers is decreasing in $p^{F}$ above its equilibrium value.

Proof. The proof is identical to the proof of Lemma 6, if one substitutes $p^{M}$ in place of $p$. The difference between these cases comes from the difference between prices $p$ and $p^{M}$. In the case of a market with middlemen, price $p$ is not directly relevant for the decision making of a farmer, because he cannot trade at this price. Even though it might seem unlikely to observe $\frac{d p^{M}}{d p^{F}}<0$ in the case with middlemen or $\frac{d p}{d p^{F}}<0$ without middlemen, our numerical example (see Figures 3-5) show that both cases are possible in general and the first is in fact prevalent. Intuitively, such an outcome happens because the probability of successful trade $\pi$ decreases enough to offset any favorable increase in price.

Lemma 13 If the participation of FT farmers decreases as $p^{F}$ increases, then the aggregate FT farmers' profits decrease.

Proof. Again, use $p^{M}$ instead of $p$ to obtain the proof.

The preceding lemmas show that it is very unlikely that the aggregate profits of any group of farmers would increase as a consequence of the excess supply Fair Trade regime. Again, the only theoretical possibility remains an increase in the aggregate Fair Trade profits. However, our numerical results produce falling aggregate profits regardless of the participation patterns. ${ }^{33}$

The present setup with monopsonistic middlemen helped us understand the effects of the introduction of a new Fair Trade market and the negative impact of a minimum binding price on both the normal farmers' incomes and the aggregate profits. Nonetheless, we would also like to analyze the relationship between the excess supply, the participation patterns of both types of farmers, the income of Fair Trade farmers and profits of the middlemen. Since the comparative statics with general demands and supply distributions proves to be excessively complex, in the next subsection we illustrate a number of model outcomes on an example with explicit functional forms.

\subsubsection{Example with explicit demands}

In this subsection, we analyze the links between participation, incomes, middlemen's profits and the excess supply on a specific example with quasilinear demand preferences

\footnotetext{
${ }^{33}$ The same holds for the simulation results in the setup without middlemen.
} 
and uniform productivity distribution. We specify demand functions using a model of consumers that considers normal and Fair Trade coffee to be imperfect substitutes. Let's assume a quasilinear utility function

$$
\begin{gathered}
\tilde{U}=U\left(x^{N}, x^{F T}\right)+Q \\
U\left(x^{N}, x^{F}\right)=\alpha\left(x^{N}+x^{F}\right)-\frac{1}{2}\left(\left(x^{N}\right)^{2}+2 \gamma x^{N} x^{F}+\left(x^{F}\right)^{2}\right) \\
\gamma \in\langle 0,1\rangle, \alpha, \delta>0,
\end{gathered}
$$

where $x^{N}$ and $x^{F}$ are consumptions of normal and FT, $Q$ is the numeraire good. Note that while Richardson and Stähler (2007) treat FT and normal products as perfect substitutes, we take an alternative approach and model the Fair Trade good as an imperfect substitute for normal coffee. In our framework, the degree of substitutability $\gamma$ is assumed to depend negatively on the "warm glow" effect discussed by Andreoni (1990), which in the present context reflects the additional utility due to the consumption of coffee grown under "fair" standards. Note that higher $\gamma$ implies a "lower warm glow effect", i.e., regular and FT coffee are easier to substitute.

Consumers maximize their utility given the budget constraint

$$
p x^{N}+p^{F} x^{F}+Q \leq M
$$

The maximization problem leads to the demand function for normal and FT coffee, respectively:

$$
\begin{aligned}
x^{N} & =\frac{\alpha}{1+\gamma}+\frac{\gamma}{1-\gamma^{2}} p^{F}-\frac{1}{1-\gamma^{2}} p, \\
x^{F} & =\frac{\alpha}{1+\gamma}+\frac{\gamma}{1-\gamma^{2}} p-\frac{1}{1-\gamma^{2}} p^{F} .
\end{aligned}
$$

\subsubsection{Numerical results}

In the following we plot three groups of graphs with our numerical results, each group capturing a specific model dimension. For all graphs, the x-axis represents the excess of the Fair Trade price $p^{F}$ above its market equilibrium value. The results have been derived for three different values of the substitution parameter $\gamma$, namely 0 (dot), 0.5 (circle) and $0.99(\mathrm{x})$.

The first group depicts the behavior of equilibrium prices $p$ and $p^{M}$ and the proportion of production going to Fair Trade $\pi$. The graphs show that the proportion of production sold on Fair Trade markets $\pi$ decreases with the excess $p^{F}$, but this effect 
is smaller if $\gamma$ is lower, i.e., when the two types of coffee are harder to substitute. In particular, lower $\gamma$ leads to a relatively milder drop in the Fair Trade demand, hence the equilibrating adjustment of $\pi$ does not have to be as pronounced.

Consistent with Lemma 10, the graphs also show that the equilibrium price $p$ on the market for normal coffee can be both increasing and decreasing with $p^{F}$, depending again on the degree of substitutability. If both types of coffee are easier to substitute (higher $\gamma$ ), then the increase in price $p^{F}$ leads to a likewise increase in the price of normal coffee $p$.

The reason for the commovement of prices $p^{F}$ and $p$ is the congruent working of the demand for normal coffee and the middleman's incentives to cut costs. ${ }^{34}$ Holding farmers' expectations regarding $\pi$ and $p$ constant, the initial rise in the Fair Trade price $p^{F}$ reduces the Fair Trade demand. The released Fair Trade output has to be rechanneled back to the middleman. With a higher degree of substituability $\gamma$, this output volume becomes larger, the middleman has a stronger incentive to lower the purchase price $p^{M}$, and more of the least productive farmers are thus pushed out of the normal coffee market. At the same time, the cross-price reaction of the demand for normal coffee rises with $\gamma$ and further dampens the extent of the potential coffee glut. As a result, for a sufficiently strong combination of the middleman's price cutting and demand cross-price effects the overall outcome might be a higher normal coffee price $p$. Our numerical results in Figure 3 conform to the theoretical possibility of a rising price $p$ in the excess-supply regime.

We have already discussed the middlemen's motivation to reduce the purchase price $p^{M}$ in the excess-supply equilibrium (see Lemma 11). The last graph illustrates how the excess supply of Fair Trade coffee strengthens the position of the middlemen relative to Fair Trade with market clearing. ${ }^{35}$ As the middlemen's profit margin increases with $\gamma$,

\footnotetext{
${ }^{34}$ Remember that such a constellation would not be possible in the world without middlemen, since there is no mechanism that would work against the downward pressure on the prices of conventional coffee.

${ }^{35}$ In our discussion of the model's adjustment mechanism, we assume that the middleman is not able to distinguish between normal and Fair Trade farmers so that she offers the same price $p^{M}$ to both groups. In other words, the middleman is not able to discriminate between the two types of producers. The middleman's ability to ration depending on the producer type would lead to the optimal response $p^{M}$ being set to zero for unsold Fair Trade production, which would in turn lower the Fair Trade farmers' expected payoffs as well as their participation in the scheme. The remaining participating farmers would then de facto play an infinite lottery with the probability $\pi$ of winning $p^{F}-c-f$ and the probability $1-\pi$ of making a loss $-(c+f)$. While we did not find any empirical evidence on middlemen's discrimination based on farmers' status, the main reason for our non-rationing assumption is that the lottery setup represents a rather special sub-case of the present model with no significant changes in results.

Of course, by decreasing $p^{M}$, the middleman forgoes some farmers on the produce/stay inactive margin, yet this amount depends on $\gamma$ only indirectly through the middleman's reaction to the released Fair Trade output.
} 

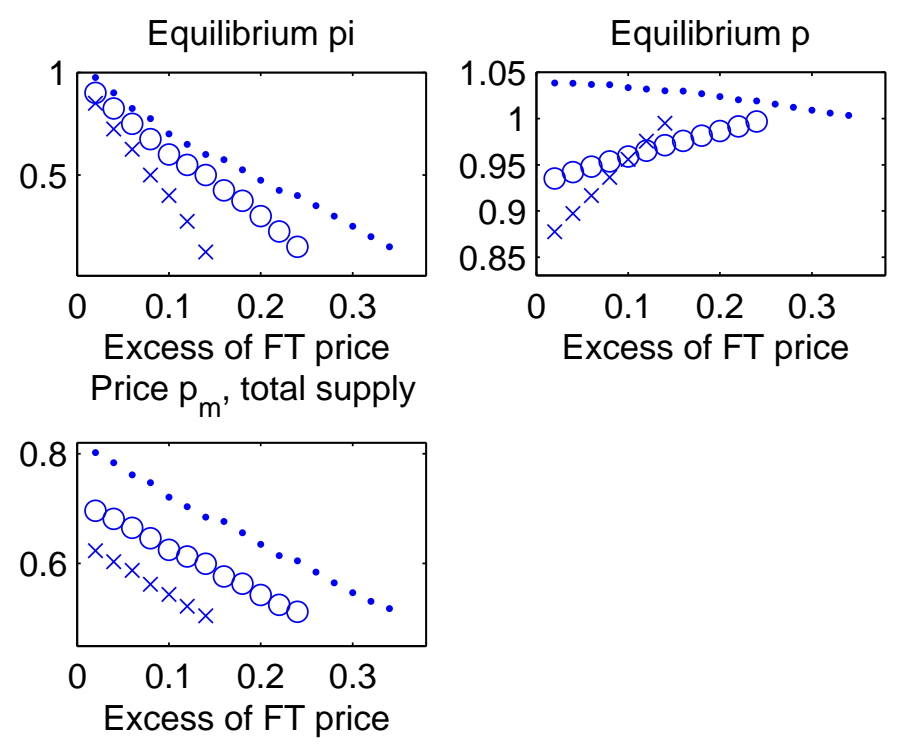

Figure 3: Equilibrium prices.

one might even observe a decline in the living standards of normal farmers and the least effective farmers leaving the market, despite a simultaneous increase in the world price of normal coffee $p$.

The second group of plots shows how profits depend on the excess of $p^{F}$ above its market equilibrium value. Farmers' aggregate profits are decreasing in the degree of substitutability between normal and Fair Trade coffee. One can also see how the Fair Trade excess supply regime benefits the middlemen and how the increasing level of $\gamma$ boosts their profits. The closer substitutes both kinds of coffee are, the faster the middlemen's profits rise both at the intensive $\left(p-p^{M}\right)$ and the extensive $\left(S^{W N}\right)$ margin.

Finally, we plot graphs that describe farmers' participation choices and realized supplies as functions of the excess-supply price $p^{F}$. The farmers' participation choices are described in plots labelled "normal supply" and "FT supply". The reader will notice that the participation in the Fair Trade scheme initially rises yet eventually decreases as the difference between FT price $p^{F}$ and market-clearing price increases. At these levels, the Fair Trade participation declines sharply as many previously Fair Trade farmers now switch back to the normal coffee production. Given that the middlemen's purchase price $p^{M}$ falls continuously, it is precisely this group of farmers that drive the postponed increase of the normal coffee supply.

The participation choices differ from the pattern of realized trades, since part of the Fair Trade harvest has to be sold through conventional markets. The plots labeled 
FT farmers profit

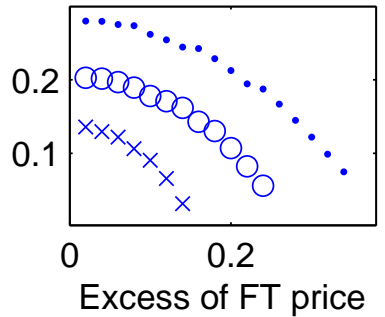

total profit

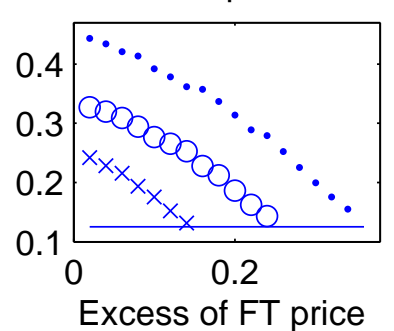

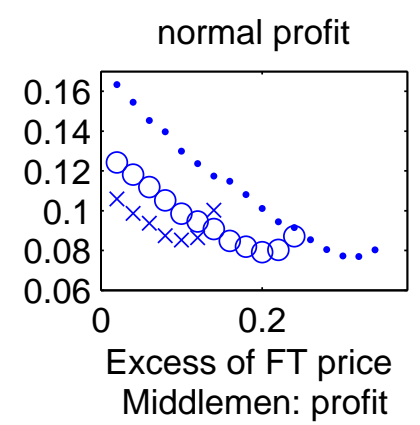

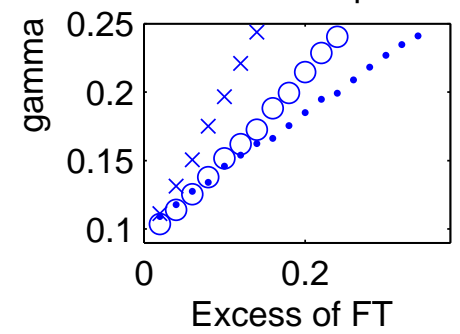

Figure 4: Equilibrium profits.
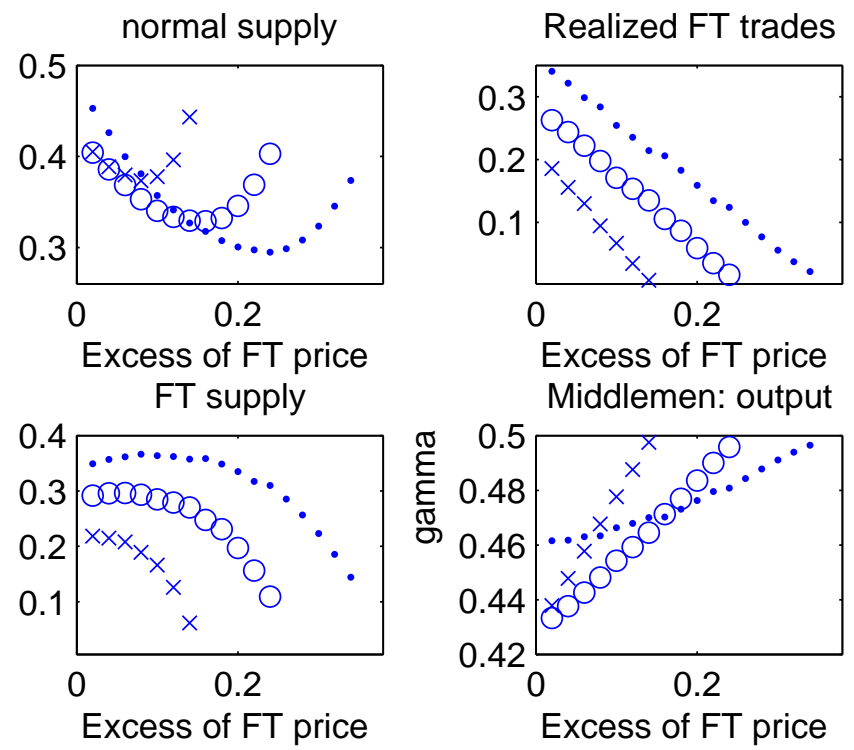

Figure 5: Equilibrium quantities 
"Realized FT trades" and "Middlemen output" capture the actual volumes of trade transacted on each market. These plots again confirm that the greatest benefactor from the excess-supply regime are in fact not the farmers, but paradoxically the middlemen.

\subsubsection{Summary of the results in the world with middlemen}

In this section we focused on the effect of the introduction of the Fair Trade market and binding minimum price $p^{F}$ in a setup with monopsonistic middlemen. Our results conform to the generally positive role for Fair Trade discussed in the previous section. Furthermore, they convey a number of additional conclusions that either complement or replace the non middlemen setup.

First of all, the common claims that the excess supply caused by the binding minimum price policy of the FLO tends to depress world prices and thus the incomes of the non-participating farmers are not quite precise. The normal coffee price $p$ might in fact increase due to the market failure in the distribution chain - the middlemen. Nonetheless, the impact on the non-participating farmers' incomes remains negative. The reason is that in the present setup there exist two channels through which Fair Trade affects the incomes of farmers. In comparison with the world without middlemen, the first channel has strengthened in that the Fair Trade market boosts incomes not only through the improved matching of farmers' output with differentiated demand, but also by dampening the market power of the middlemen. The second channel, i.e. the negative impact of the minimum price $p^{F}$, has however likewise became stronger. The minimum contracting price policy now returns part of the market power back to the middlemen, who in fact become the greatest benefactors of this regime relative to the Fair Trade market with flexible price.

\section{Conclusion}

The recent success story of Fair Trade has provoked a lively debate on the scope and intensity of the scheme's actual benefits and shortcomings. We develop a simple framework and find that the introduction of a new Fair Trade market has the capacity to improve the living conditions of all farmers. The scheme's potential is not fully met, however, as the FTO's supplementary policy of a minimum contracting price brings about costs in terms of the lower-than-possible payoffs of the majority of farmers, the higher-than-necessary exit of the non-participating farmers from the coffee production, and less resources for community investment. The above equilibrium Fair Trade price 
can be justified merely as a policy of increasing farmers' participation within the Fair Trade scheme.

The major beneficiary of the minimum price policy are paradoxically the middlemen whose allegedly exploitative position stood at the very roots of the whole Fair Trade movement. In our numerical example we show that the middlemen use their monopsony position to appropriate part of the farmers' payoffs that would have been realized under the market-clearing setup. The excess supply thus allows the middlemen to exploit the farmers more than they could in the case of market clearing on the Fair Trade market. The profitability of the excess-supply regime for the middlemen also raises with the substitutability (as measured by $\gamma$ ) between normal and Fair Trade coffee. For a high degree of substitutability, one might even observe an increase in the world price of normal coffee $p$ and a simultaneous decline in the living standards of normal farmers.

Our paper does not focus on certain aspects of Fair Trade, including the impact on migration and the local environment, self-governance, credibility or the nation-wide reallocation of resources. By no means do we claim that these concerns are of lesser or no importance. Nonetheless, given the absence of an integrated modelling approach, we focus on a specific area of interest and analyze it within a well-defined framework. This area relates to the distributional impact of the Fair Trade scheme.

The model's results should serve as a comment on the potential risks and limitations of the otherwise relatively successful Fair Trade scheme. It seems quite reasonable that the very existence of Fair Trade alleviates the informational asymmetry between "socially-conscious" Western consumers, distributors and farmers located in developing countries. Given that consumers value "fair" production, the absence of credible information and non-negligible fixed costs related to setting up markets hinders the functioning of the Fair Trade market and some sort of market intervention thus might be justified. Nonetheless, the scheme's optimal design remains an open question and we hope to provide at least a partial answer.

From the policy perspective, we agree that the guaranteed minimal $p^{F}$ can take a number of other important roles such as insurance against volatile coffee prices or an improved outside option for the farmers participating in sharecropping agreements. Our results should rather be understood as a selective contribution to the debate on the benefits of alternative policy instruments. For example, the stability of Fair Trade prices can be achieved through other instruments than a fixed minimum price. The related problem of the excess supply on Fair Trade markets can be addressed e.g. through the introduction of a pre-determined schedule and gradual replacement of established Fair Trade producers by their less experienced counterparts. 


\section{Appendix}

\subsection{Model without middlemen}

\subsubsection{Comparative statics}

Proof of Lemma 3. To show that

$$
\frac{d \pi}{d p^{F}}<0, \frac{d p}{d p^{F}}<0
$$

take the total derivatives of the market equilibrium conditions and rearrange them to obtain

$$
\begin{gathered}
\left(S^{F}+\pi S_{\pi}^{F}\right) \frac{d \pi}{d p^{F}}+\left(\pi S_{p}^{F}-D_{p}^{F}\right) \frac{d p}{d p^{F}}=D_{p^{F}}^{F}-\pi S_{p^{F}}^{F} \\
S_{\pi}^{W N} \frac{d \pi}{d p^{F}}+\left(S_{p}^{W N}-D_{p}^{N}\right) \frac{d p}{d p^{F}}=D_{p^{F}}^{N}-S_{p^{F}}^{W N} \\
S^{F}=G\left(\pi\left(p^{F}-p\right)\right) \\
S^{N}=G(p)-G\left(\frac{\pi\left(p^{F}-p\right)}{k}\right) \\
S^{W F}=\pi S^{F}=\pi G\left(\frac{\pi\left(p^{F}-p\right)}{k}\right) \\
S^{W N}=G(p)-\pi G\left(\frac{\pi\left(p^{F}-p\right)}{k}\right)
\end{gathered}
$$

where

$$
\begin{gathered}
t=\frac{\pi\left(p^{F}-p\right)}{k} \\
S_{\pi}^{F}=g(t) \frac{p^{F}-p}{k}, S_{p}^{F}=-g(t) \frac{\pi}{k}, S_{p^{F}}^{F}=g(t) \frac{\pi}{k} \\
S_{\pi}^{W N}=-\pi\left(g(t) \frac{p^{F}-p}{k}\right)-S^{F} \\
S_{p}^{W N}=g(p)+\pi(g(t)) \frac{\pi}{k} \\
S_{p^{F}}^{W N}=-\pi g(t) \frac{\pi}{k} .
\end{gathered}
$$

Substituting for supply relationships and expressed in a convenient matrix form we obtain: 


$$
\left[\begin{array}{cc}
S^{F}+\pi g(t) \frac{p^{F}-p}{k} & \left.-\left(g(t) \frac{\pi^{2}}{k}\right)+D_{p}^{F}\right) \\
-\pi g(t) \frac{p^{F}-p}{k}-S^{F} & g(p)+\pi(g(t)) \frac{\pi}{k}-D_{p}^{N}
\end{array}\right]\left[\begin{array}{c}
\frac{d \pi}{d p^{F}} \\
\frac{d p}{d p^{F}}
\end{array}\right]=\left[\begin{array}{c}
D_{p^{F}}^{F}-g(t) \frac{\pi^{2}}{k} \\
D_{p^{F}}^{N}+g(t) \frac{\pi^{2}}{k}
\end{array}\right]
$$

Note that the signs of the individual cells are unambiguous:

$$
\left[\begin{array}{ll}
+ & - \\
- & +
\end{array}\right]\left[\begin{array}{c}
\frac{d \pi}{d p^{F}} \\
\frac{d p}{d p^{F}}
\end{array}\right]=\left[\begin{array}{l}
- \\
+
\end{array}\right]
$$

Rearranging comparative statics one gets

$$
\begin{aligned}
\frac{d \pi}{d p^{F}} & =\frac{D_{p^{F}}^{F}-g(t) \frac{\pi^{2}}{k}}{S^{F}+\pi g(t) \frac{p^{F}-p}{k}}+\frac{\left.\left(g(t) \frac{\pi^{2}}{k}\right)+D_{p}^{F}\right)}{S^{F}+\pi g(t) \frac{p^{F}-p}{k}} \frac{d p}{d p^{F}} \\
\frac{d \pi}{d p^{F}} & =-\frac{D_{p^{F}}^{N}+g(t) \frac{\pi^{2}}{k}}{S^{F}+\pi g(t) \frac{p^{F}-p}{k}}-\frac{g(p)+\pi(g(t)) \frac{\pi}{k}-D_{p}^{N}}{S^{F}+\pi g(t) \frac{p^{F}-p}{k}} \frac{d p}{d p^{F}}
\end{aligned}
$$

Equations (5) and (6) give us comparative statics in the FT market with the equilibrium values of $\frac{d \pi}{d p^{F}}$ and $\frac{d p}{d p^{F}}$. Of course, in the overall equilibrium both equations have to be satisfied simultaneously, which allows us to compute both $\frac{d \pi}{d p^{F}}$ and $\frac{d p}{d p^{F}}$.

Given our demand assumptions, a closer look at the system tells us that

$$
\frac{D_{p^{F}}^{F}-g(t) \frac{\pi^{2}}{k}}{S^{F}+\pi g(t) \frac{p^{F}-p}{k}}<-\frac{D_{p^{F}}^{N}+g(t) \frac{\pi^{2}}{k}}{S^{F}+\pi g(t) \frac{p^{F}-p}{k}} \text { and } 0<\frac{\left.\left(g(t) \frac{\pi^{2}}{k}\right)+D_{p}^{F}\right)}{S^{F}+\pi g(t) \frac{p^{F}-p}{k}}<-\frac{g(p)+\pi(g(t)) \frac{\pi}{k}-D_{p}^{N}}{S^{F}+\pi g(t) \frac{p^{F}-p}{k}}
$$

because we assume that the direct price effect is stronger than the indirect one: $\left|D_{p^{F}}^{F}\right|>$ $D_{p^{F}}^{N},\left|D_{p}^{N}\right|>D_{p}^{F}$. This implies that the solution has to satisfy $\frac{d \pi}{d p^{F}}<0, \frac{d p}{d p^{F}}<0$. This is easy to see - while both relationships are not linear, the intercept of (5) is unambiguously lower than the intercept of (6), while the slope of (5) is positive yet not as steep as that of (6). This implies that both curves (given that they exist and are continuous, which we assume) can cross only in the $3^{\text {rd }}$ quadrant, ${ }^{36}$ or in other words

$$
\frac{d \pi}{d p^{F}}<0, \frac{d p}{d p^{F}}<0
$$

36 Alternatively, one can express $\frac{d p}{d p^{F}}$ from (5) and (6) to see that the sign has to be negative:

$$
\frac{d p}{d p^{F}}=-\frac{\frac{D_{p}^{F}-\pi^{2} / k}{2 S^{F}}+\frac{D_{p}^{N}+\pi^{2} / k}{2 S^{F}}}{\frac{D_{p}^{N}-\left(1+\pi^{2}\right) / k}{2 S^{F}}+\frac{\left(\pi^{2} / k+D_{p}^{F}\right)}{2 S^{F}}}<0
$$

Once this is established, one can infer that $\frac{d \pi}{d p^{F}}<0$ from (5). 


\subsubsection{The impact of Fair Trade on farmers' payoffs and participation}

Proof of Lemma 4. 1) In the excess-supply equilibrium, the farmers' participation in the Fair Trade scheme increases if and only if

$$
\left|\varepsilon_{p^{F}}^{D^{F}}\right|<\left|\varepsilon_{p^{F}}^{\pi}\right| \text { and }\left|\varepsilon_{p^{F}}^{D^{N}} \frac{S^{W N}}{S^{W F}}\right|<\left|\varepsilon_{p^{F}}^{\pi}\right|
$$

The payoffs of farmers participating in Fair Trade decrease unambiguously relative to the market-clearing case.

- We are interested in the sign of $\frac{d S^{F}\left(\pi, p, p^{F}\right)}{d p^{F}}$, where $S^{F}\left(\pi, p, p^{F}\right)$ corresponds to participation in the Fair Trade certification scheme.

In the excess-supply equilibrium with $\pi<1$ it has to hold that

$$
\begin{gathered}
\pi S^{F}\left(\pi, p, p^{F}\right)=D^{F}\left(p, p^{F}\right) \\
S^{N}\left(\pi, p, p^{F}\right)+(1-\pi) S^{F}\left(\pi, p, p^{F}\right)=D^{N}\left(p, p^{F}\right), \\
\pi=\pi\left(p^{F}\right), p=p\left(p^{F}\right) .
\end{gathered}
$$

Consider an increase of $p^{F}$ above its equilibrium value. In the new equilibrium, the realized FT supply $\pi S^{F}$ has to match the FT demand $D^{F}$, hence it has to hold that

$$
\begin{aligned}
\frac{d\left[\pi S^{F}\left(\pi, p, p^{F}\right)\right]}{d p^{F}} & =\frac{d D^{F}}{d p^{F}} \\
S^{F}\left(\pi, p, p^{F}\right) \frac{d \pi}{d p^{F}}+\pi \frac{d S^{F}\left(\pi, p, p^{F}\right)}{d p^{F}} & =\frac{d D^{F}}{d p^{F}} \\
\frac{d S^{F}\left(\pi, p, p^{F}\right)}{d p^{F}} & =\frac{1}{\pi}\left(\frac{d D^{F}}{d p^{F}}-S^{F}\left(\pi, p, p^{F}\right) \frac{d \pi}{d p^{F}}\right) \\
\operatorname{sign}\left(\frac{d S^{F}\left(\pi, p, p^{F}\right)}{d p^{F}}\right) & =\operatorname{sign}\left(\frac{d D^{F}}{d p^{F}}-S^{F}\left(\pi, p, p^{F}\right) \frac{d \pi}{d p^{F}}\right) \\
\operatorname{sign}\left(\frac{d S^{F}\left(\pi, p, p^{F}\right)}{d p^{F}}\right) & =\operatorname{sign}\left(\frac{d D^{F}}{d p^{F}}-\frac{D^{F}}{\pi} \frac{d \pi}{d p^{F}}\right) .
\end{aligned}
$$

Pre-multipying the term in the brackets by $\frac{p^{F}}{D^{F}}>0$, one gets

$$
\operatorname{sign}\left(\frac{d S^{F}\left(\pi, p, p^{F}\right)}{d p^{F}}\right)=\operatorname{sign}\left(\frac{p^{F}}{D^{F}} \frac{d D^{F}}{d p^{F}}-\frac{p^{F}}{\pi} \frac{d \pi}{d p^{F}}\right)=\operatorname{sign}\left(\varepsilon_{p^{F}}^{D^{F}}-\varepsilon_{p^{F}}^{\pi}\right) .
$$


Finally, since $\frac{d \pi}{d p^{F}}$ and $\frac{d D^{F}}{d p^{F}}$ are both negative, we have

$$
\frac{d S^{F}\left(\pi, p, p^{F}\right)}{d p^{F}}>0 \Longleftrightarrow\left|\varepsilon_{p^{F}}^{D^{F}}\right|<\left|\varepsilon_{p^{F}}^{\pi}\right| .
$$

- For the second part of Lemma 4 we use the fact that

$$
\begin{aligned}
S^{F} & =G\left(\frac{\pi\left(p^{F}-p\right)}{k}\right) \\
S^{W N} & =S^{N}+(1-\pi) S^{F}=G(p)-\pi G\left(\frac{\pi\left(p^{F}-p\right)}{k}\right),
\end{aligned}
$$

hence

$$
\operatorname{sign}\left(\frac{d S^{F}\left(\pi, p, p^{F}\right)}{d p^{F}}\right)=\operatorname{sign}\left[\left(p^{F}-p\right) \frac{d \pi}{d p^{F}}+\pi\left(1-\frac{d p}{d p^{F}}\right)\right]
$$

Take the total derivative of the normal coffee market equilibrium condition 1 ,

$$
\begin{aligned}
\frac{d\left[S^{W N}\left(\pi, p, p^{F}\right)\right]}{d p^{F}}= & \frac{d D^{N}}{d p^{F}} \\
\frac{d\left[G(p)-\pi G\left(\frac{\pi\left(p^{F}-p\right)}{k}\right)\right]}{d p^{F}}= & \frac{d D^{N}}{d p^{F}} \\
\frac{1}{k}\left[\left(p^{F}-p\right) \frac{d \pi}{d p^{F}}+\pi\left(1-\frac{d p}{\left.\left.d p^{F}\right)\right]=}\right.\right. & -\frac{\left(D_{p}^{N} \frac{d p}{d p^{F}}+D_{p^{F}}^{N}\right)}{\pi g\left(\frac{\pi\left(p^{F}-p\right)}{k}\right)}+\frac{g(p)}{\pi g\left(\frac{\pi\left(p^{F}-p\right)}{k}\right)} \frac{d p}{d p^{F}}- \\
& -\frac{G\left(\frac{\pi\left(p^{F}-p\right)}{k}\right)}{\pi g\left(\frac{\pi\left(p^{F}-p\right)}{k}\right)} \frac{d \pi}{d p^{F}},
\end{aligned}
$$

which implies

$$
\operatorname{sign}\left(\frac{d S^{F}\left(\pi, p, p^{F}\right)}{d p^{F}}\right)=\operatorname{sign}\left[\begin{array}{c}
-\left(D_{p^{F}}^{N}+G\left(\frac{\pi\left(p^{F}-p\right)}{k}\right) \frac{d \pi}{d p^{F}}\right)+ \\
\left(g(p)-D_{p}^{N}\right) \frac{d p}{d p^{F}}
\end{array}\right] .
$$


Knowing that $\frac{d p}{d p^{F}}<0$, multiply the term in the brackets by $\frac{p^{F}}{\pi}>0$ and

$$
\frac{G(p)-\pi G\left(\frac{\pi\left(p^{F}-p\right)}{k}\right)}{G(p)-\pi G\left(\frac{\pi\left(p^{F}-p\right)}{k}\right)}=1
$$

to obtain

$$
\operatorname{sign}\left(\frac{d S^{F}\left(\pi, p, p^{F}\right)}{d p^{F}}\right)=\operatorname{sign}\left[(-1)\left(\varepsilon_{p^{F}}^{D^{N}} \frac{S^{W N}}{S^{W F}}+\varepsilon_{p^{F}}^{\pi}\right)\right]
$$

That is,

$$
\frac{d S^{F}\left(\pi, p, p^{F}\right)}{d p^{F}}>0 \Longleftrightarrow\left|\varepsilon_{p^{F}}^{D^{N}} \frac{S^{W N}}{S^{W F}}\right|<\left|\varepsilon_{p^{F}}^{\pi}\right| .
$$

2) In the excess-supply equilibrium without middlemen, the Fair Trade farmers' payoffs decrease unambiguously.

To show that the participating farmers' payoffs decrease unambiguously, note that

$$
\frac{d \pi}{d p^{F}}<\frac{D_{p^{F}}^{F}}{G\left(\frac{\pi\left(p^{F}-p\right)}{k}\right)}
$$

implies $\frac{d p}{d p^{F}}<0$, so for more negative values of $\frac{d \pi}{d p^{F}}$ the change in farmer's revenues from FT becomes less and less favorable. In other words,

$$
\frac{d \pi}{d p^{F}}=\frac{D_{p^{F}}^{F}}{G\left(\frac{\pi\left(p^{F}-p\right)}{k}\right)}
$$

represents the marginal value of $\frac{d \pi}{d p^{F}}$ consistent with transition to a new equilibrium. Now

$$
\frac{d \pi}{d p^{F}}=\frac{D_{p^{F}}^{F}}{G\left(\frac{\pi\left(p^{F}-p\right)}{k}\right)} \rightarrow \frac{d p}{d p^{F}}=0
$$

and we have

$$
\frac{d}{d p^{F}}\left(\frac{\pi p^{F}+(1-\pi) p}{k}\right)=\frac{1}{k}[\pi+\underbrace{\left(p^{F}-p\right) \frac{d \pi}{d p^{F}}}_{<0}+\underbrace{(1-\pi) \frac{d p}{d p^{F}}}_{<0}]=\frac{1}{k}[\pi+\underbrace{\left(p^{F}-p\right) \frac{d \pi}{d p^{F}}}_{<0}] .
$$


But we also know that for $\frac{d \pi}{d p^{F}}=\frac{D_{p F}^{F}}{G\left(\frac{\left.\pi p^{F}-p\right)}{k}\right)}$

$$
\left(p^{F}-p\right) \frac{d \pi}{d p^{F}}=-\frac{k D_{p^{F}}^{F}}{\pi g\left(\frac{\pi\left(p^{F}-p\right)}{k}\right)}+\frac{k}{\pi g\left(\frac{\pi\left(p^{F}-p\right)}{k}\right)} \frac{d D^{F}}{d p^{F}}-\pi
$$

so that

$$
\begin{gathered}
\frac{d}{d p^{F}}\left(\frac{\pi p^{F}+(1-\pi) p}{k}\right)=\frac{1}{k}[\pi+\underbrace{\left(p^{F}-p\right) \frac{d \pi}{d p^{F}}}_{<0}+\underbrace{(1-\pi) \frac{d p}{d p^{F}}}_{<0}]= \\
\frac{1}{\pi g\left(\frac{\pi\left(p^{F}-p\right)}{k}\right)}\left[-D_{p^{F}}^{F}+\frac{d D^{F}}{d p^{F}}\right]=\frac{1}{\pi g\left(\frac{\pi\left(p^{F}-p\right)}{k}\right)}\left[D_{p}^{F} \frac{d p}{d p^{F}}\right]=0,
\end{gathered}
$$

which is the best possible impact on the Fair Trade farmers' payoffs that is consistent with the excess-supply equilibrium.

Proof of Corollary 5. Following the rise of the Fair Trade price, the participation in the Fair Trade scheme can increase despite the fall of the participating farmers' payoffs.

The total derivative of the Fair Trade participation equals

$$
\begin{aligned}
\frac{d G\left(\frac{\pi\left(p^{F}-p\right)}{k}\right)}{d p^{F}} & =\underbrace{g\left(\frac{\pi\left(p^{F}-p\right)}{k}\right)}_{>0}\left[\frac{d}{d p^{F}}\left(\frac{\pi\left(p^{F}-p\right)}{k}\right)\right]= \\
& =\frac{1}{k} g\left(\frac{\pi\left(p^{F}-p\right)}{k}\right)\left[\frac{d\left(\pi p^{F}+(1-\pi) p\right)}{d p^{F}}-\frac{d p}{d p^{F}}\right],
\end{aligned}
$$

where

$$
g(x)=\frac{d G(x)}{d(x)}
$$

Hence the sign of the total derivative depends on the sign of the part in square brackets. Even if the Fair Trade payoffs decline after the move from $\pi=1$, i.e.,

$$
\frac{d\left(\pi p^{F}+(1-\pi) p\right)}{d p^{F}}<0
$$

the bracketed term can be positive since $-\frac{d p}{d p^{F}}>0$. 


\subsection{Model with middlemen}

\subsubsection{Existence of equilibria with middlemen}

In order to proceed with the analysis, we will assume that there exists an equilibrium in which both markets are active, and which generates market-clearing prices $p$ and $p^{F}$, i.e. an equilibrium in which $\pi=1$. This section informally discusses under which conditions the equilibrium will exist. We do not claim that these conditions are necessary, as the existence of the equilibrium is not of our primary interest. In particular, we discuss the price ranges for which one may hope to find an equilibrium.

The market-clearing conditions are

$$
\begin{array}{rll}
\text { FT market } & : & D^{F}\left(p, p^{F}\right)=G\left(\left(p^{F}-p^{M}\right) / k\right)=S^{F}\left(p^{F}, p^{M}\left(p, p^{F}\right)\right) \\
\text { Normal market } & : & D^{N}\left(p, p^{F}\right)=S^{N}\left(p^{F}, p^{M}\left(p, p^{F}\right)\right)=G\left(p^{M}\right)-G\left(\left(p^{F}-p^{M}\right) / k\right) .
\end{array}
$$

Obviously, we may have equilibrium only if

$$
0 \leq S^{F} \leq 1,0 \leq S^{N} \leq 1, S^{F}+S^{N} \leq 1
$$

We will be interested in those equilibria in which both markets are active. In case of a uniform distribution $G(x)=x, g(x)=1$, we can discuss a range of prices for which there might be an equilibrium.

$$
0<S^{F}, 0<S^{N}, S^{F}+S^{N} \leq 1
$$

The last constraint can be expressed in the form

$$
\frac{p}{2}+\frac{p^{F}}{2(k+1)} \leq 1
$$

The other two constraints are

$$
(2 k+1) p^{F}-p(1+k)>0, p+k p-p^{F}>0 .
$$

The possible combination of prices $p, p^{F}$ is the triangle on the following picture.

We can see that if $k$ decreases, which means that it is relatively cheaper for all farmers to produce FT coffee, the set of prices that might correspond to an equilibrium 


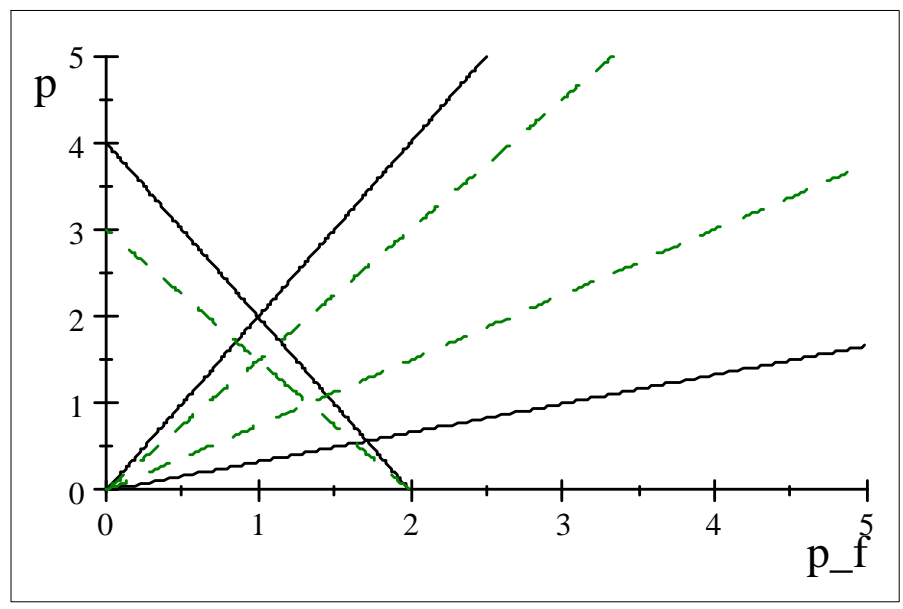

Feasible combinations of $p, p^{F}$ for equilibria.

Figure 6: Participation constraints depending on $p, p^{F}$ for $k=1$ (full line) and $k=0.5$ (dashed line) .

shrinks. This is an intuitive result - for very low $k$, it is cheap to obtain an FT certificate and thus prices on the regular market $(p)$ must be close to the FT prices $\left(p^{F}\right)$ in the market equilibrium. Note that this result holds in the excess supply equilibrium with appropriate modifications to the picture ( $p^{F}$ has to be replaced with $\pi p^{F}$ on the supply side). The expected value from participation in the FT and regular markets must be similar if the participation costs in the FT market are low.

\subsubsection{The impact of Fair Trade on farmers' payoffs and participation with the middlemen}

Proof of Lemma 9. All farmers are better off if and only if the price $p^{M}$ offered by the middlemen increases once the FT market opens. This happens if the overall demand for coffee does not fall substantially, i.e., if the world price of normal coffee $p$ is relatively insensitive to the price of $\mathrm{FT}$ coffee $p^{F}$, or if it actually increases as a result of the new FT market. It is easy to observe that compared to the situation without Fair Trade, all farmers benefit only if the price of coffee set by middleman $p^{M}$ increases and such increases indeed attract new farmers. If the price $p^{M}$ decreases, some FT farmers might be better off than before, but there is a group of farmers who stop selling coffee altogether. These farmers lose, since in the absence of FT they used to make small yet positive profits. In general, the middleman's price $p^{M}$ might move both ways, because the movement of the price $p$ is ambiguous and might dominate the other effects working through the Fair Trade price $p^{F}$ or the success rate $\pi$. Nonetheless, it is easy to show 
that for fixed $p$, price $p^{M \prime}$ in the world with an active FT market is larger than $p^{M}$ when an FT market does not exist. To see this, compare the first order conditions of the middleman:

[no FT] $: \quad\left(p-p^{M}\right) g\left(p^{M}\right)-G\left(p^{M}\right)=0$

$[\mathrm{FT}]: \quad\left(p^{\prime}-p^{M \prime}\right)\left[g\left(p^{M \prime}\right)+\frac{1}{k} g\left(\frac{p^{F \prime}-p^{M \prime}}{k}\right)\right]-\left[G\left(p^{M \prime}\right)-G\left(\frac{p^{F \prime}-p^{M \prime}}{k}\right)\right]=0$.

It is obvious that once we plug in the values of $p^{M}$ and $p$ from the first line, the last element on the second line, $G\left(p^{M}\right)-G\left(\frac{p^{F}-p^{M}}{k}\right)$, is smaller than $G\left(p^{M}\right)$. Also, trivially $\frac{1}{k} g\left(\frac{p^{F}-p^{M}}{k}\right)>0$. Thus, if we plug in $p^{M}$ from the first FOC into the second one and evaluate the sign, we see that

$$
\left(p-p^{M}\right) g\left(p^{M}\right)-G\left(p^{M}\right)+\left(p-p^{M}\right) \frac{1}{k} g\left(\frac{p^{F}-p^{M}}{k}\right)+G\left(\frac{p^{F}-p^{M}}{k}\right)>0
$$

or alternatively,

$$
\left(p-p^{M}\right)\left[g\left(p^{M}\right)+\frac{1}{k} g\left(\frac{p^{F}-p^{M}}{k}\right)\right]>\left[G\left(p^{M}\right)-G\left(\frac{p^{F}-p^{M}}{k}\right)\right] .
$$

Since the marginal gains in revenues from additional normal coffee purchases exceed the corresponding marginal costs for $p^{M}$ from the world without Fair Trade, it is optimal for the middleman to raise the purchase price to $p^{M \prime}$. Thus the inequality implies that $p^{M \prime}>p^{M}$.

This argument requires that the first order condition of the FT market middleman is monotonic (unique local maximum) and that $p$ is fixed. If the world price $p$ is not very sensitive to the introduction of FT coffee (e.g., the FT market is small), then the argument holds by continuity (expression (10) remains positive for small changes in $p$ ). It is obvious to see that if $p$ actually increases, then the argument holds as well, so the only case when it might not hold is when $p$ decreases significantly as a result of the FT market opening. However, this can only happen once the overall world demand declines sharply after the introduction of Fair Trade, which is consistent with our results from Lemma 2 that dealt with the world without the middlemen. In fact, the results for the market-clearing case with the middlemen are slightly stronger than those in Lemma 2. In the world with the middlemen, the non-participating farmers are better off even if the price of the normal coffee does not change. This happens as a consequence of the strategic behavior of the middleman, who finds it profitable to adjust her price $p^{M}$ slightly in order to mute the outflow of farmers towards Fair Trade. Hence the non- 
participating farmers can fare better despite the possible fall of the normal coffee price $p$, given that the decline is not too sharp.

\subsubsection{Comparative statics in the world with middlemen}

Proof of Lemma 10. Again, similarly to the excess supply analysis without the middlemen we differentiate the whole system (4):

$$
\begin{aligned}
S^{F} \frac{d \pi}{d p^{F}}+\pi\left(S_{\pi}^{F} \frac{d \pi}{d p^{F}}+S_{p^{M}}^{F}\left(\frac{\partial p^{M}}{\partial p^{F}}+\frac{\partial p^{M}}{\partial \pi} \frac{d \pi}{d p^{F}}+\frac{\partial p^{M}}{\partial p} \frac{d p}{d p^{F}}\right)+S_{p^{F}}^{F}\right) & =D_{p}^{F} \frac{d p}{d p^{F}}+D_{p^{F}}^{F} \\
S_{\pi}^{W N} \frac{d \pi}{d p^{F}}+S_{p^{M}}^{W N}\left(\frac{\partial p^{M}}{\partial p^{F}}+\frac{\partial p^{M}}{\partial \pi} \frac{d \pi}{d p^{F}}+\frac{\partial p^{M}}{\partial p} \frac{d p}{d p^{F}}\right)+S_{p^{F}}^{W N} & =D_{p}^{N} \frac{d p}{d p^{F}}+D_{p^{F}}^{N},
\end{aligned}
$$

where $S_{\pi}^{W N}$ is a partial derivative of $S^{W N}$ with respect to $\pi$, for example.

Rearranging, one gets

$$
\begin{aligned}
\left(S^{F}+\pi S_{\pi}^{F}+\pi \frac{\partial p^{M}}{\partial \pi} S_{p^{M}}^{F}\right) \frac{d \pi}{d p^{F}}+ & \left(\pi S_{p}^{F}+\pi \frac{\partial p^{M}}{\partial p} S_{p^{M}}^{F}-D_{p}^{F}\right) \frac{d p}{d p^{F}}= \\
& =D_{p^{F}}^{F}-\pi S_{p^{F}}^{F}-\pi S_{p^{M}}^{F} \frac{\partial p^{M}}{\partial p^{F}} \\
\left(S_{\pi}^{W N}+S_{p^{M}}^{W N} \frac{\partial p^{M}}{\partial \pi}\right) \frac{d \pi}{d p^{F}}+ & \left(S_{p}^{W N}-D_{p}^{N}+S_{p^{M}}^{W N} \frac{\partial p^{M}}{\partial p}\right) \frac{d p}{d p^{F}} \\
& =D_{p^{F}}^{N}-S_{p^{F}}^{W N}-\frac{\partial p^{M}}{\partial p^{F}} S_{p^{M}}^{W N}
\end{aligned}
$$

We can plug in for $S^{F}, S^{N}, S^{F}, S^{W F}, S^{W N}$ and their derivatives:

$$
\begin{gathered}
S^{F}=G\left(\frac{\pi\left(p^{F}-p^{M}\right)}{k}\right) \\
S^{N}=G(p)-G\left(\frac{\pi\left(p^{F}-p^{M}\right)}{k}\right) \\
S^{W F}=\pi S^{F}=\pi G\left(\frac{\pi\left(p^{F}-p^{M}\right)}{k}\right) \\
S^{W N}=G\left(p^{M}\right)-\pi G\left(\frac{\pi\left(p^{F}-p^{M}\right)}{k}\right)
\end{gathered}
$$




$$
\begin{aligned}
\pi S_{\pi}^{F}+\pi \frac{\partial p^{M}}{\partial \pi} S_{p^{M}}^{F} & =g(t)\left(\frac{p^{F}-p^{M}}{k}-\frac{\pi}{k} \frac{\partial p^{M}}{\partial \pi}\right) \\
\pi S_{p}^{F}+\pi \frac{\partial p^{M}}{\partial p} S_{p^{M}}^{F} & =-g(t) \frac{\pi^{2}}{k} \frac{\partial p^{M}}{\partial p} \\
\pi S_{p^{F}}^{F}+\pi S_{p^{M}}^{F} \frac{\partial p^{M}}{\partial p^{F}} & =\pi g(t) \frac{\pi}{k}-\frac{\pi^{2}}{k} g(t) \frac{\partial p^{M}}{\partial p^{F}} \\
S_{\pi}^{W N}+S_{p^{M}}^{W N} \frac{\partial p^{M}}{\partial \pi} & =g\left(p^{M}\right) \frac{\partial p^{M}}{\partial \pi}-\pi g(t)\left(\frac{p^{F}-p^{M}}{k}-\frac{\pi}{k} \frac{\partial p^{M}}{\partial \pi}\right)-S^{F} \\
S_{p}^{W N}+S_{p^{M}}^{W N} \frac{\partial p^{M}}{\partial p} & =\left(g\left(p^{M}\right)+\pi g(t) \frac{\pi}{k}\right) \frac{\partial p^{M}}{\partial p} \\
S_{p^{F}}^{W N}+\frac{\partial p^{M}}{\partial p^{F}} S_{p^{M}}^{W N} & =\left(g\left(p^{M}\right)+\pi g(t) \frac{\pi}{k}\right) \frac{\partial p^{M}}{\partial p^{F}}-\pi g(t) \frac{\pi}{k} \\
t & =\frac{\pi\left(p^{F}-p^{M}\right)}{k} .
\end{aligned}
$$

We can rewrite the equations (11) into matrix form

$$
\begin{aligned}
& {\left[\begin{array}{cc}
S^{F}+\pi g(t)\left(\frac{p^{F}-p^{M}}{k}-\frac{\pi}{k} \frac{\partial p^{M}}{\partial \pi}\right) & -g(t) \frac{\pi^{2}}{k} \frac{\partial p^{M}}{\partial p}-D_{p}^{F} \\
g\left(p^{M}\right) \frac{\partial p^{M}}{\partial \pi}-\pi g(t)\left(\frac{p^{F}-p^{M}}{k}-\frac{\pi}{k} \frac{\partial p^{M}}{\partial \pi}\right)-S^{F} & \left(g\left(p^{M}\right)+\pi g(t) \frac{\pi}{k}\right) \frac{\partial p^{M}}{\partial p}-D_{p}^{N}
\end{array}\right]\left[\begin{array}{c}
\frac{d \pi}{d p^{F}} \\
\frac{d p}{d p^{F}}
\end{array}\right]=} \\
& {\left[\begin{array}{c}
D_{p^{F}}^{F}-g(t) \frac{\pi^{2}}{k} \\
D_{p^{F}}^{N}-\left(g\left(p^{M}\right)+\pi g(t) \frac{\pi}{k}\right) \frac{\partial p^{M}}{\partial p^{F}}+\pi g(t) \frac{\pi}{k}
\end{array}\right] .}
\end{aligned}
$$

Note that the signs of the individual cells depend on the size of $\frac{\partial p^{M}}{\partial \pi}$

$$
\begin{gathered}
{\left[\begin{array}{l}
+ \\
- \\
-
\end{array}\right]\left[\begin{array}{c}
\frac{d \pi}{d p^{F}} \\
\frac{d p}{d p^{F}}
\end{array}\right]=\left[\begin{array}{l}
- \\
+
\end{array}\right]} \\
S^{F}+\pi g(t)\left(\frac{p^{F}-p^{M}}{k}-\frac{\pi}{k} \frac{\partial p^{M}}{\partial \pi}\right)>0 \\
-g(t) \frac{\pi^{2}}{k} \frac{\partial p^{M}}{\partial p}-D_{p}^{F}<0 \\
g\left(p^{M}\right) \frac{\partial p^{M}}{\partial \pi}-\pi g(t)\left(\frac{p^{F}-p^{M}}{k}-\frac{\pi}{k} \frac{\partial p^{M}}{\partial \pi}\right)-S^{F}<0 \\
\left(g\left(p^{M}\right)+\pi g(t) \frac{\pi}{k}\right) \frac{\partial p^{M}}{\partial p}-D_{p}^{N}>0 .
\end{gathered}
$$

From Lemma 9, we know that $\frac{\partial p^{M}}{\partial \pi}>0$, so we need $\frac{\partial p^{M}}{\partial \pi}$ to be small for this result to hold. 
For notational simplicity, we will write

$$
\left[\begin{array}{ll}
A & B \\
C & D
\end{array}\right]\left[\begin{array}{c}
\frac{d \pi}{d p^{F}} \\
\frac{d p}{d p^{F}}
\end{array}\right]=\left[\begin{array}{l}
E \\
F
\end{array}\right] .
$$

To show that

$$
\frac{d p}{d p^{F}}<0 \text { and } \frac{d \pi}{d p^{F}}>0
$$

is not possible, we need to show that if $\frac{d \pi}{d p^{F}}>0$, then $\frac{d p}{d p^{F}}>0$. To do this, we write

$$
\begin{aligned}
A \frac{d \pi}{d p^{F}}+B \frac{d p}{d p^{F}} & =E \\
C \frac{d \pi}{d p^{F}}+D \frac{d p}{d p^{F}} & =F .
\end{aligned}
$$

We know that $A>0>C, D>0>B, F>0>E$. So if $\frac{d \pi}{d p^{F}}>0, A>0$, but $E<0$, it must be that $B \frac{d p}{d p^{F}}<0$ in equilibrium, which means, because $B<0$, that $\frac{d p}{d p^{F}}>0$. The same argument holds for the second equation: $F>0$, the first element $\left(C \frac{d \pi}{d p^{F}}<0\right)$ is negative, so the second element on the second line must be positive. Since $D>0$, it implies $\frac{d p}{d p^{F}}>0$. So the previous results about the impossibility of $\frac{d \pi}{d p^{F}}>0$ and $\frac{d p}{d p^{F}}>0$ seem to be preserved.

Thus, we have the following combinations that are of theoretical interest:

$$
\begin{aligned}
& \frac{d p}{d p^{F}}<0, \text { and } \frac{d \pi}{d p^{F}}<0 \\
& \frac{d p}{d p^{F}}>0, \text { and } \frac{d \pi}{d p^{F}}<0 .
\end{aligned}
$$

Other possibilities are either not interesting or impossible:

$$
\begin{aligned}
& \frac{d p}{d p^{F}}>0 \text { and } \frac{d \pi}{d p^{F}}>0 \text { (not interesting) } \\
& \frac{d p}{d p^{F}}<0, \text { and } \frac{d \pi}{d p^{F}}>0 \text { (not possible). }
\end{aligned}
$$

So one can see that an increase in FT price $p^{F}$ leads to an increased excess supply, but the impact on the world price is ambiguous $p .^{37}$

\footnotetext{
${ }^{37}$ Note that the effect on the world price, even if theoretically predicted, is likely to be extremely small given the relative sizes of both markets. Thus, the result is more of a theoretical interest than a testable prediction.
} 


\subsection{Aggregate farmers' profits}

Proof of Lemma 6. Unless the world price of coffee $p$ increases significantly when the price of FT coffee increases, the aggregated profit of all farmers is decreasing in $p^{F}$ above the market equilibrium.

Revenues of the farmers in the excess-supply regime without middlemen is

$$
\begin{gathered}
R=S^{W N} p+S^{W F} p^{F}=\left(S^{N}+S^{F}\right) p+\pi S^{F}\left(p^{F}-p\right), \\
S^{F}=G\left(\frac{\pi\left(p^{F}-p\right)}{k}\right) \\
S^{N}=G(p)-G\left(\frac{\pi\left(p^{F}-p\right)}{k}\right) \\
R=G\left(p^{M}\right) p+\pi G\left(\frac{\pi\left(p^{F}-p\right)}{k}\right)\left(p^{F}-p\right) .
\end{gathered}
$$

The costs are slightly more complicated:

$$
\begin{gathered}
C=\int_{0}^{t}(k+1) c g(c) d c+\int_{t}^{p} c g(c) d c \\
C=\int_{0}^{p^{M}} c g(c) d c+k \int_{0}^{t} c g(c) d c, \\
t=\frac{\pi\left(p^{F}-p\right)}{k} .
\end{gathered}
$$

These costs change with the change in $p^{F}$ in the following way:

$$
\begin{aligned}
\frac{d C}{d p^{F}} & =p g(p) \frac{d p}{d p^{F}}+k t g(t) \frac{\pi}{k}\left(1-\frac{d p}{d p^{F}}\right)+k \operatorname{tg}(t) \frac{p^{F}-p}{k} \frac{d \pi}{d p^{F}} \\
& =p g(p) \frac{d p}{d p^{F}}+k \operatorname{tg}(t)\left(\frac{d \pi}{d p^{F}} \frac{p^{F}-p}{k}+\frac{\pi}{k}\left(1-\frac{d p}{d p^{F}}\right)\right)
\end{aligned}
$$

The change in revenues is

$$
\begin{aligned}
& \frac{d R}{d p^{F}}=\frac{d p}{d p^{F}}(G(p)+p g(p))+\frac{d \pi}{d p^{F}} G(t)\left(p^{F}-p\right)+\pi\left(p^{F}-p\right) g(t) \frac{d t}{d p^{F}}+\pi G(t)\left(1-\frac{d p}{d p^{F}}\right), \\
& \frac{d t}{d p^{F}}=\frac{d \pi}{d p^{F}}\left(p^{F}-p\right) / k+\frac{\pi}{k}\left(1-\frac{d p}{d p^{F}}\right) .
\end{aligned}
$$


Note that

$$
\frac{d R}{d p^{F}}-\frac{d C}{d p^{F}}=\frac{d p}{d p^{F}}\left(G(p)-\pi G\left(\frac{\pi\left(p^{F}-p\right)}{k}\right)\right)+\frac{d \pi}{d p^{F}}\left(G(t)\left(p^{F}-p\right)\right) .
$$

Since $\pi \leq 1$ and $\frac{\pi\left(p^{F}-p\right)}{k} \leq p$ in an equilibrium, the outcome depends on the sign of $\frac{d p}{d p^{F}}$ and $\frac{d \pi}{d p^{F}}$. We have already shown that $\frac{d \pi}{d p^{F}}<0$ in any relevant equilibrium. Thus, unless $\frac{d p}{d p^{F}}>0$ and is large enough, the profit of all farmers is decreasing in $p^{F}$ above the market equilibrium.

Proof of Lemma 7. If the participation of FT farmers decreases as a result of an increase in $p^{F}$, then the overall FT farmers' profit decreases.

The revenue and costs of FT farmers:

$$
\begin{aligned}
R & =G(t)\left(\pi p^{F}+(1-\pi) p\right)=G(t)(k t+p) \\
C & =\int_{0}^{t}(k+1) c g(c) d c .
\end{aligned}
$$

We can compute the derivatives:

$$
\begin{aligned}
\frac{d R}{d p^{F}} & =g(t)(k t+p) \frac{d t}{d p^{F}}+G(t)\left(k \frac{d t}{d p^{F}}+\frac{d p}{d p^{F}}\right) \\
\frac{d C}{d p^{F}} & =(k+1) \operatorname{tg}(t) \frac{d t}{d p^{F}}, \\
\frac{d t}{d p^{F}} & =\frac{d \pi}{d p^{F}}\left(p^{F}-p\right) / k+\frac{\pi}{k}\left(1-\frac{d p}{d p^{F}}\right) .
\end{aligned}
$$

The difference is

$$
\begin{aligned}
\frac{d R}{d p^{F}}-\frac{d C}{d p^{F}} & =g(t)(k t+p) \frac{d t}{d p^{F}}+G(t)\left(k \frac{d t}{d p^{F}}+\frac{d p}{d p^{F}}\right)-(k+1) \operatorname{tg}(t) \frac{d t}{d p^{F}} \\
& =\frac{d t}{d p^{F}} g(t)\left(p-\pi \frac{p^{F}-p}{k}+k G(t)\right)+G(t) \frac{d p}{d p^{F}} .
\end{aligned}
$$

Note that

$$
g(t)\left(p-\pi \frac{p^{F}-p}{k}+k G(t)\right)>0
$$

and thus

$$
\frac{d t}{d p^{F}}<0, \frac{d p}{d p^{F}}<0 \Longrightarrow \frac{d R}{d p^{F}}-\frac{d C}{d p^{F}}<0
$$




\subsection{Small FT market - fixed $p$}

We extend our analysis to the situation when the FT market is too small to impact the world price $p$ of coffee. For example, we may assume that there is a large number of regions, but in only very few of them are farmers participating in Fair Trade. Middlemen, if present, adjust to the FT market only if there are FT farmers in their region.

Lemma 14 If there are no middlemen, the Fair Trade market where the price is set to clear the market always helps the farmers.

Proof. Since price $p$ does not change, the number of active farmers $G(p)$ does not change. Those farmers who decide to sell on the FT market $\left(G\left(\frac{p^{F}-p}{k}\right)\right.$ of them) are all better off, because they could have stayed in the non-FT market

In the world where the FT market clears, but there are middlemen, the situation is slightly more complicated. Middlemen react to the FT market and thus alter the revenue of non-FT farmers. However, we have shown before that all active farmers are strictly better off if the price $p^{M}$ increases and that this happens when $p$ is not very sensitive to $p^{F}$. We can thus apply the same argument as in Lemma 9 here, because price $p$ is assumed to be fixed. For fixed $p$, the argument is very intuitive - middlemen increase price to attract more farmers to offset the loss from those who left for the FT market. This increase in price helps all non-FT farmers, but FT farmers are still better off than non-FT ones.

Lemma 15 When the FT market clears, it helps all the farmers even if there are middlemen.

Proof. See Lemma 9 and note that $p$ is fixed.

In the case of the FT market with price $p^{F}$ above market equilibrium (and thus $\pi<1$ ), but no middlemen, we will analyze the impact of a small increase in $p^{F}$. Farmers benefit if the expected revenue, $\pi p^{F}$, increases. This happens when

$$
\begin{aligned}
\frac{\partial\left(\pi p^{F}\right)}{\partial p^{F}} & =\frac{\partial \pi}{\partial p^{F}} p^{F}+\pi>0 \\
\frac{\partial \pi}{\partial p^{F}} & >-\frac{\pi}{p^{F}} .
\end{aligned}
$$

We can use market equilibrium conditions to prove the following result. 
Lemma 16 Farmers benefit from a marginal increase in $p^{F}$ if and only if

$$
\frac{D_{p^{F}}^{F}\left(p, p^{F}\right)-\pi^{2} g(t) / k}{G(t)+t g(t)}>-\frac{\pi}{p^{F}},
$$

where $t=\pi \frac{p^{F}-p}{k}$.

Proof. We use comparative statics to show that

$$
\begin{aligned}
D^{F}\left(p, p^{F}\right)-\pi G(t) & =0 \\
\frac{\partial \pi}{\partial p^{F}} & =\frac{D_{p^{F}}^{F}\left(p, p^{F}\right)-\frac{\pi^{2}}{k} g(t)}{G(t)+\operatorname{tg}(t)}<0,
\end{aligned}
$$

because $D_{p^{F}}^{F}<0$. From the previous discussion, we know that farmers benefit from the FT market if $\frac{\partial \pi}{\partial p^{F}}$ is large enough:

$$
\frac{\partial \pi}{\partial p^{F}}=\frac{D_{p^{F}}^{F}\left(p, p^{F}\right)-\frac{\pi^{2}}{k} g(t)}{G(t)+t g(t)}>-\frac{\pi}{p^{F}} .
$$

The final case, excess supply on the FT market and middlemen on the normal coffee market, is slightly more complicated. Because of the middlemen, farmers don't get a fixed price $p$ for their normal coffee but price $p^{M}$ that in general depends on the price $p^{F}$. The equilibrium condition on the FT market is

$$
\begin{aligned}
D^{F}\left(p, p^{F}\right) & =\pi G\left(t^{\prime}\right) \\
t^{\prime} & =\pi \frac{p^{F}-p^{M}}{k} .
\end{aligned}
$$

Lemma 17 If middlemen never increase their price $p^{M}$ more than the price on the FT market increased, $\frac{\partial p^{M}}{\partial p^{F}}<1$, and they do not increase their price too much when the probability of success on the FT market increases:

$$
\frac{\partial p^{M}}{\partial \pi}<k \frac{t^{\prime}}{\pi^{2}}\left(\frac{G\left(t^{\prime}\right)}{t^{\prime} g\left(t^{\prime}\right)}+1\right)
$$

then the probability of successful trade on the FT market decreases when the FT price increases. 
Proof. We can again use the comparative statics argument to show

$$
\frac{\partial \pi}{\partial p^{F}}=\frac{D_{p^{F}}^{F}-\frac{\pi^{2}}{k} g\left(t^{\prime}\right)\left(1-\frac{\partial p^{M}}{\partial p^{F}}\right)}{G\left(t^{\prime}\right)+\pi g\left(t^{\prime}\right)\left(\frac{t^{\prime}}{\pi}-\frac{\pi}{k} \frac{\partial p^{M}}{\partial \pi}\right)} .
$$

Assuming that

$$
\frac{\partial p^{M}}{\partial p^{F}}<1, \frac{\partial p^{M}}{\partial \pi}<k \frac{t^{\prime}}{\pi^{2}}\left(\frac{G\left(t^{\prime}\right)}{t^{\prime} g\left(t^{\prime}\right)}+1\right)
$$

and by observing that

$$
G\left(t^{\prime}\right)+\pi g\left(t^{\prime}\right)\left(\frac{t^{\prime}}{\pi}-\frac{\pi}{k} \frac{\partial p^{M}}{\partial \pi}\right)>0 \Longleftrightarrow \frac{\partial p^{M}}{\partial \pi}<k \frac{t^{\prime}}{\pi^{2}}\left(\frac{G\left(t^{\prime}\right)}{t^{\prime} g\left(t^{\prime}\right)}+1\right)
$$

we can conclude that $\frac{\partial \pi}{\partial p^{F}}<0$.

Note that this lemma also allows for the possibility that the probability of success on the FT market $(\pi)$ is locally increasing in $p^{F}$. This happens when $\frac{\partial p^{M}}{\partial p^{F}}$ is very large and such a condition is rather intuitive. If middlemen increase the price relative to an increase in $p^{F}$, it is possible that more FT farmers switch back to regular coffee production. However, this effect has to be stronger than a decrease in demand by FT coffee consumers. It is clear that such a case is very unlikely.

\section{References}

Andreoni, J., "Impure Altruism and Donations to Public Goods: A Theory of WarmGlow Giving", The Economic Journal, 100, 464-477, 1990

Bacon, Ch., "Confronting the Coffee Crisis: Can Fair Trade, Organic, and Specialty Coffees Reduce Small-Scale Farmer Vulnerability in Northern Nicaragua?", World Development, 33, 497-511, 2005

Broda, Ch. and Weinstein, E. D., "Globalization and the Gains from Variety", The Quarterly Journal of Economics, 121(2), 541-585, 2006

CEPAL, "Centroamérica: El Impacto de la Caídea de los Precios del Café", Comisión Económica para América Latina y el Caribe LC/MEX/L.517, Mexico, 2002

Dixit, K. A. and Stiglitz, E. J., "Monopolistic Competition and Optimum Product Diversity“, American Economic Review, 67(3), 297-308, 1977

EFTA, "Fair Trade Yearbook: Towards 2000", European Fair Trade Association, Maastricht, 1998 
European Commission, "Communication from the Commission to the Council on 'Fair Trade' ", available at http://eur-lex.europa.eu/smartapi/cgi/sga _doc?smartapi!celexplus!prod!DocNumber\&lg=en\&type_doc=COMfinal\&an _doc=1999\&nu_doc=619, Brussels, 1999

Feenstra, C. R., "New Product Varieties and the Measurement of International Prices", American Economic Review, 84(1), 157-77, 1994

FINE, "Fair Trade in Europe 2005: Facts and Figures on Fair Trade in 25 European Countries", available at http://www.fairtrade-advocacy.org/ftineurope2005.html, Fair Trade Advocacy Office, Brussels, 2005

FLO, "Shaping Global Partnerships: Fair Trade Labelling Organizations International Annual Report 2006/2007", available at http://www.fairtrade.net/uploads/media/Final_FLO_AR_2007_03.pdf, Fair Trade Organizations International, 2007

FTF, "2005 Report: Fair Trade Trends in North America and the Pacific Rim", available at http://www.equiterre.org/equitable/pdf/2005_FTF_Trends_Report.pdf, The Fair Trade Federation, 2006

Giovanucci, D., "Sustainable Coffee Survey of the North American Specialty Coffee Industry", Philadelphia, PA, Summit Foundation, 2001

ICO, International Coffee Organization Trade Statistics, available at http://dev.ico.org/prices/m1a.htm, 2007

Lindsey, B., "Grounds for Complaint? Understanding the 'Coffee Crisis'", Trade Briefing Paper 16, Cato Institute Center for Trade Policy Studies, Washington DC, 2003

Manning, A., Monopsony in Motion: Imperfect Competition in Labor Markets, Princeton University Press, 2003

Melitz, M. J., "The Impact of Trade on Intra-Industry Reallocations and Aggregate Industry Productivity", Econometrica, 71(6), 1695-1725, 2003

Milford, A., "Coffee, Cooperatives and Competition: The Impact of Fair Trade", Chr. Michelsen Institute Report, 2004

Miron, A. J., "The Effect of Drug Prohibition on Drug Prices: Evidence from the Markets for Cocaine and Heroin", The Review of Economics and Statistics, 85(3), $522-530,2003$ 
Moore, G., "The Fair Trade Movement: Parameters, Issues and Future Research", Journal of Business Ethics, 53, 73-86, 2004

Petrin, A., "Quantifying the Benefits of New Products: The Case of the Minivan", Journal of Political Economy, 110(4), 705-729, 2002

Podhorsky, A., "Environmental Labeling", $\quad$ http://www.cergeei.cz/pdf/events/papers/060220_t.pdf, Job Market Paper, 2006

Raynolds, T. L., "Consumer/Producer Links in Fair Trade Networks", Sociologia Ruralis, 42, 404-424, 2002

Raynolds, T. L., "Poverty Alleviation Through Participation in Fair Trade Coffee Networks: Existing Research and Critical Issues", background paper prepared for the project funded by the Community and Resource Development Program, Ford Foundation, 2002

Ronchi, L., "The Impact of Fair Trade on Producers and Their Organizations: A Case Study with Coocafé in Costa Rica", PRUS Working paper 11, 2002

Talbot, J. M., "Where Does Your Coffee Dollar Go? The Division of Income and Surplus along the Coffee Commodity Chain", Studies in Comparative International Development, 32, 56-91

The Economist, "Voting with Your Trolley: Food Politics", December 7th, 2006

Washington Post, "Gift-Wrapped Guilt? My Adventure with Ethical Shopping", available at http://www.washingtonpost.com/wpdyn/content/article/2005/12/16/AR2005121601688.html, 2005

Wasserman, M., "Trouble in Coffee Lands", available at www.bos.frb.org/economic/nerr/rr2002/q2/coffee.htm, Federal Reserve Bank of Boston Regional Review, 12, 4-13, 2002

Weber, J., "Fair Trade Coffee Enthusiasts Should Confront Reality", Cato Journal, 27, 109-117, 2007

Winters, A., McCulloch, N. and McKay, A., "Trade Liberalization and Poverty: The Evidence so Far", Journal of Economic Literature, 42, 72-115, 2004 
Individual researchers, as well as the on-line and printed versions of the CERGE-EI Working Papers (including their dissemination) were supported from the following institutional grants:

- Center of Advanced Political Economy Research [Centrum pro pokročilá politickoekonomická studia], No. LC542, (2005-2009),

- Economic Aspects of EU and EMU Entry [Ekonomické aspekty vstupu do Evropské unie a Evropské měnové unie], No. AVOZ70850503, (2005-2010);

- Economic Impact of European Integration on the Czech Republic [Ekonomické dopady evropské integrace na ČR], No. MSM0021620846, (2005-2011);

Specific research support and/or other grants the researchers/publications benefited from are acknowledged at the beginning of the Paper.

(c) Tomáč Konečný, Jan Mysliveček, 2008

All rights reserved. No part of this publication may be reproduced, stored in a retrieval system or transmitted in any form or by any means, electronic, mechanical or photocopying, recording, or otherwise without the prior permission of the publisher.

Published by

Charles University in Prague, Center for Economic Research and Graduate Education (CERGE) and

Economics Institute ASCR, v. v. i. (EI)

CERGE-El, Politických vězňů 7, 11121 Prague 1, tel.: +420 224005 153, Czech Republic.

Printed by CERGE-EI, Prague

Subscription: CERGE-EI homepage: http://www.cerge-ei.cz

Editors: Directors of CERGE and EI

Managing editors: Deputy Directors for Research of CERGE and EI

ISSN 1211-3298

ISBN 978-80-7343-167-9 (Univerzita Karlova. Centrum pro ekonomický výzkum

a doktorské studium)

ISBN 978-80-7344-156-2 (Národohospodářský ústav AV ČR, v. v. i.) 
CERGE-EI

P.O.BOX 882

Politických vězňů 7

11121 Praha 1

Czech Republic http://www.cerge-ei.cz 